\title{
Larval morphology of Heterogynis (Lepidoptera: Heterogynidae)
}

\author{
Francesca VEGLIANTE and Alberto ZILLI*
}

Museum of Zoology, Via U. Aldrovandi 18, 00197 Rome, Italy

Key words. Zygaenoidea, Heterogynidae, larval morphology, chaetotaxy, phylogenetics

\begin{abstract}
The external morphology and chaetotaxy of the larvae of Heterogynidae (Lepidoptera) are described in order to provide information of potential phylogenetic value for the reconstruction of the systematic relationships within the Zygaenoidea. The most outstanding characteristics of heterogynid larvae are their modified habitus during diapause, the presence of an epipharyngeal lamella, the shape of the prothoracic shield, the presence in the first instar of an organ of unknown function on the middorsum of the mesothorax ("Chapman's organ"), the absence of V2, V3 and Va on the head, the absence of V1 on the prothorax and the presence of two primary setae on the inner side of the proleg, the last trait representing an autapomorphy of the family. A number of possible synapomorphies with the Zygaenidae (e.g. presence of cuticular cavities) suggest a close relationship between these two families, but other larval and adult traits are shared only with the "Phaudinae" and limacodid-group families of the Zygaenoidea (viz. absence of V1 on the prothorax with the "Phaudinae", reduced proboscis and absence of ocelli with them all). Nevertheless, a lack of knowledge of the preimaginal instars of species from some zygaenoid families, and of the homology and polarity of given characters of groups within and outside the Zygaenoidea, hamper a thorough comparison of larvae.
\end{abstract}

\section{INTRODUCTION}

The lepidopterous family Heterogynidae Rambur, 1866 is mostly known for the peculiar life cycle of its members and currently only includes the western Palaearctic genus Heterogynis Rambur, 1837 (Zilli, 1998; Epstein et al., 1999). In fact, another genus Janseola Hopp, 1923, from southern Africa (Hopp, 1923; Seitz \& Gaede, 1926), which was associated with this family actually belongs to the Zygaenidae: Procridinae (Zilli, 1998). The genus Heterogynis encompasses eight species diagnosable on morphological, bionomical and genetical grounds, but there is evidence that a number of additional biospecies exists (Daniel, 1966; Zilli, 1987; Zilli et al., 1988a, 1988b; Zilli \& Racheli, 1989; Zilli, 2002; Freina, 2003a, 2003b), particularly within the so-called penella complex, which was shown to be composed of an array of allopatric morphologically similar species (Zilli, 1987; Zilli et al., 1988b).

Following the discovery of the first representative, viz. Heterogynis penella (Hübner, [1819]), the extreme sexual dimorphism and bizarre bionomics of Heterogynis attracted the attention of several early authors (e.g. Rambur, 1837; Graslin, 1850; Chenu, 1851-1853; Bruand, 1853; Schmidt, 1860). Nevertheless, it was Chapman (1898, 1902, 1904, 1905, 1916) who first made detailed observations, often unrivalled, on the morphology and behaviour of $H$. penella, H. paradoxa Rambur, 1837 and H. canalensis Chapman, 1904. More modern contributions on the topic are by Daniel \& Dierl (1966), Minet (1986), Naumann (1988), Zilli and co-workers (Zilli et al., 1988b; Zilli \& Racheli, 1990), Freina \& Witt (1990a, 1990b), Guenin (1997a) and Freina (2003a, 2003b).

Males of Heterogynis are normally winged and fly during the day, but the females undergo a regressive metamorphosis (catametaboly) that results in a somatic organisation even simpler than that of the larvae. They retain numerous larval traits, including ten distinct abdominal segments; they are apterous and live permanently bound to their pupal exuviae, the legs being reduced to tiny stumps sunk into their cuticle. Depending on the species, the females can emerge from or remain concealed inside their cocoons. In the morning, they protrude from a slit in the pupal exuviae for a few hours, calling for males. This cycle is repeated for 1-3 days and if they do not succeed in copulating they die hanging down from the exuviae. Soon after mating, the fertilized females re-enter their pupal cases where they oviposit and wait until the eggs hatch. Before leaving the cocoon and searching for a suitable host-plant, the young caterpillars devour their still living mother. Matrivory in Heterogynis was interpreted as cannibalistic parental care, which enhances the offspring's chances of survival (Zilli \& Racheli, 1990), because the females contain rich fatty deposits (Daniel \& Dierl, 1966).

The systematic position of the Heterogynidae has long been debated, with competing opinions on their association either with the Zygaenoidea or the Tineoidea. Early views were largely based on gross phenetic considerations emphasizing the resemblance of Heterogynis with members of the Zygaenidae or that they have similar sexual dimorphism and peculiar life habits to the Psychidae (Tineoidea) (e.g. Rambur, 1837; Bruand, 1853). Keener morphological insights quite regularly led the Heterogynidae to be associated with the Zygaenoidea (e.g. Karsch, 1898; Rebel, 1898; Forbes, 1910), sometimes as a part of the Zygaenidae (Börner, 1939). In contrast, Brock (1971) delegated the group to the Tineoidea on the basis of some characters of the imago, although the available information on the larvae is taken as evidence

\footnotetext{
* Corresponding author. E-mail: a.zilli@comune.roma.it
} 
for placing them within the Zygaenoidea (Witthohn \& Naumann, 1984; Minet, 1986, 1991; Epstein et al., 1999). Nevertheless, the preimaginal morphology of Heterogynis has only been partially assessed, as only Dyar (1895), Chapman (1898) and Forbes (1910) provided very limited information on the chaetotaxy. Therefore the aim of the present work is to provide detailed morphological information on larvae of the Heterogynidae in order to better address the issue of their phylogenetic relationships.

\section{MATERIAL AND METHODS}

Mature larvae of Heterogynis penella (Hübner, [1819]) and H. eremita Zilli, Cianchi, Racheli \& Bullini, 1988, were collected near Aschi Alto (Abruzzi, Central Italy) and on Mt. Pollino (Calabria, Southern Italy), respectively, and reared to the adult stage. Adults copulated in captivity and their offspring was used to obtain samples of all preimaginal instars. Some larvae were frozen and stored in a refrigerator $\left(\mathrm{T}=-18^{\circ} \mathrm{C}\right)$ until they were used for observation, others were preserved in $70 \%$ ethanol, a number of them after boiling in distilled water for 10-20 seconds. Boiling the larvae caused them to extend and they were principally used to assess the chaetotaxy. Approximately 100 larvae of $H$. penella and 50 larvae of $H$. eremita were examined. After examination, the specimens were either preserved in $70 \%$ ethanol or permanently mounted in Euparal.

To test for the presence of pinacula, larvae were stained either with $1 \%$ Mercurochrome solution or $0.75 \%$ Chlorazol Black in $75 \%$ ethanol. The study of the head chaetotaxy required the clearing of the cephalic capsules, which are heavily sclerotized in all but the first larval instar. This was performed either by boiling the head capsules in $10 \% \mathrm{KOH}$ solution for $20-30 \mathrm{sec}-$ onds and leaving them in cold $10 \% \mathrm{KOH}$ for 1 day or by soaking them in cold $10 \% \mathrm{KOH}$ for 3 days.

Specimens immersed in distilled water or $70 \%$ ethanol were examined with the aid of stereoscopic microscopes (Wild M5 and Wild MZ8, both equipped with a camera lucida and Zeiss SR). For the observation of minute morphological details, the relevant pieces were mounted in Euparal or placed in distilled water on a slide and examined under a stereo binocular or a compound microscope (Olympus $\mathrm{BH} 2$, equipped with a camera lucida).

The dorsal head retractor muscles were observed by dissecting specimens that had been preserved in $70 \%$ ethanol without prior boiling, as this procedure would have damaged the soft internal structures. Dissections were performed in Petridishes containing a layer of paraffin wax, using watchmaker's forceps, miniature scissors (Vannas-Moria 9600) and micropins ("Minutien"), on specimens immersed in 70\% ethanol. Drawings were made with the aid of a camera lucida.

Nomenclature of setae, pores and stemmata follows Hasenfuss (1980), with the following exceptions and additions. Stehr's (1987a) terminology is adopted for the "ocellar" (O) and "subocellar" (SO) setae that are here termed "stemmatal" (S) and "substemmatal" (SS), respectively, in agreement with the current notation of larval eyes. Accordingly, McIndoo's (1919) "subocellar" pores SOb and SOc, as well as "ocellar" pore $\mathrm{Ob}$ (McIndoo, 1929), not mentioned by Hasenfuss (1980), were termed $\mathrm{SSb}, \mathrm{SSc}$ and $\mathrm{Sb}$, respectively. The terminology of Grimes \& Neunzig (1986a, 1986b) was followed for the sensilla of the apical segment of the maxillary palp and lobe, as their description is more complete than that of Hasenfuss (1980). For the same reason, Gerasimov's (1952) terminology for the antennal sensilla was used, because he extended Ripley's (1923) nomenclature by naming the antennal pore and supernumerary sensilla basiconica. Since labral pores were not named by
Hasenfuss (1980), and other authors only distinguished the most proximal one as Ia (Forbes, 1910) or Lra (McIndoo, 1919), a new nomenclature is suggested here. On the basis of their position, all labral pores are considered to belong to the M-group; letters are assigned to them starting from the base of the labrum and moving distally. Nomenclature of the proleg crochets follows Stehr (1987a) and Stehr \& Martinat (1987). In the description of the head chaetotaxy, the term "anterior" means "nearer to the mouthparts", and the term "ventral" relates to the structures located near to the mentum and hypostoma, i.e. a prognathous orientation of the head is assumed.

In the figures all the setae were drawn black in order to guarantee a better rendering of the setal pattern, although they are colourless and transparent, with the noticeable exception of the dark setae STII and STIII on the maxillary lobe.

\section{RESULTS}

\section{Habitus}

Heterogynis larvae show a normal eruciform body structure, with five pairs of prolegs on abdominal segments 3-6 and 10 (Fig. 1). The head is a shiny dark brown, and it is generally maintained partially retracted into the prothorax, particularly after the first moult. Newly emerged caterpillars of $H$. penella and $H$. eremita are pale yellow, except for the head, legs and prothoracic shield, which are dark brown. The anal shield is absent. A few days after emergence, six longitudinal dark stripes appear on the body of the first instar larva: one mediodorsal, one medioventral, paired laterals (dorsal to the spiracles, but occasionally embracing them) and paired lateroventrals. The stripes are brownish in the first instar and become black after the first moult, giving rise to a characteristic black and yellow pattern that is interpreted as aposematic by most authors (e.g. Zilli \& Racheli, 1990), although Chapman (1902) considered it to be cryptic in H. paradoxa. The pigmentation is not in the cuticle, as the black is due to an epidermal pigment and yellow to the blood.

\section{Cuticular processes and appendages}

The head cuticle is smooth, that of the trunk and legs finely spinulose. The spinules are of variable length, the longest nearly attaining the size of microsetae (only in the first instar are they longer) (Fig. 2b, d-e). In the last instars, the spinules on the leg sclerites become much sparser, while part of the body spinules undergo sclerotization. Exceptions are represented by the spinules located on intersegmental areas and, in female larvae (H. eremita, particularly), those that lie on the yellow stripes of the body, so the darkening of spinules conforms to the striped pattern. In males all the non-intersegmental spinules tend to undergo sclerotization, but the spinules are usually less developed than those of females. H. eremita differs from $H$. penella in having more robust and longer spinules. This fact is especially noteworthy as the larvae of $H$. eremita are smaller than those of $H$. penella. The cuticle of diapausing larvae is not spinulose, but rippled.

After the first moult, another kind of cuticular process appears, the "coronetted tubercles" (Chapman, 1904) (Fig. 2f-g). They are distributed rather regularly on the unsclerotized parts of the trunk, except for the ventral 

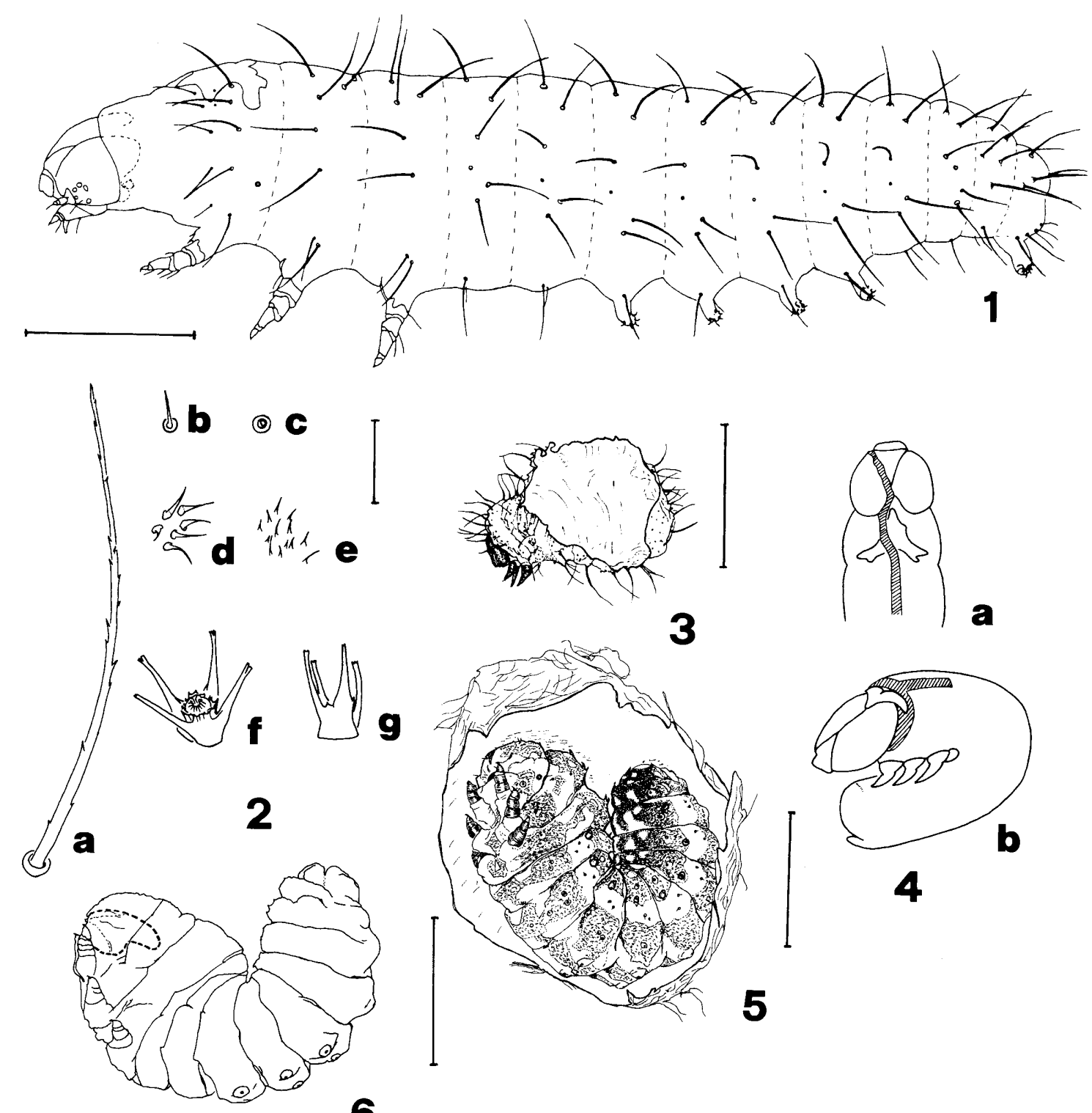

Figs 1-6. 1 - first instar larva of Heterogynis penella $($ scale bar $=0.5 \mathrm{~mm}) ; 2$ - cuticular processes and appendages of $H$. eremita (female last instar larva): (a) seta AL3; (b) microseta; (c) pore AVa; (d) sclerotized spinules from a black zone of the trunk; (e) unsclerotized spinules from a yellow zone of the trunk; (f, g), coronetted tubercles (scale bar $=0.1 \mathrm{~mm}$ ); $3-$ larval exuvia of $H$. penella (second moult) (scale bar $=1 \mathrm{~mm}$ ); 4 - ecdysial lines at pupation (schematic): (a) male; (b) female; 5 - diapausing larva of H. penella (fourth instar) inside a hibernaculum (scale bar $=1 \mathrm{~mm}) ; 6$ - sketch of diapausing larva showing position of the head $(H$. penella, fourth instar) (scale bar $=1 \mathrm{~mm})$.

areas of the leg- and proleg-bearing segments. Their number increases with successive moults, but the newly developed tubercles are smaller than the older ones. The coronetted tubercles of second instar larvae are strongly sclerotized cylinders with the upper base open and bordered with spines. In later instars, 2-6 long branches appear, often ramified at their tip, which protrude from the outer surface of each cylinder. The shape of coronetted tubercles in all but the second instar is quite different in the two species examined; in H. penella, the spines are longer and the branches are more clearly ramified than those of H. eremita. It is worth noticing that the upper, "open" base of the coronetted tubercles is in reality covered by a thin, radially folded membrane, strongly suggestive of a valvular opening of cuticular cavities of
"Zygaena-type" for the storage of cyanoglucosides, which were observed in Heterogynis by Epstein et al. (1999). In fact, the morphology of the membrane corresponds with that of the valvular openings described by Naumann \& Povolný (1987) for the small cuticular cavities of Zygaena punctum Ochsenheimer, 1808. Coronetted tubercles are missing in diapausing larva.

The tactile setae of head and legs, with the exception of $\mathrm{Cx} 2$, are simple; those on the thorax and abdomen are weakly plumose (Fig. 2a), except for some simple setae located on the ventral area of the body, i.e. all V1 setae, SV2 on the proleg-bearing segments, and AL4, AV1, AV2, AV3, AV4 on the anal segment. Setal papillae are in the form of sclerotized rings, slightly protruding from the integument. Microsetae can be distinguished from the 
longest cuticular spinules by the sclerotized rings surrounding their bases. Nearly all head pores are bordered by dark sclerotized rings. It was not possible to detect sclerotized pinacula with the staining methods used.

\section{Moulting}

The process of moulting in Heterogynis is peculiar, as the larval cuticle splits along the mediodorsal line starting from the caudal extremity, but the ecdysial line does not reach the thorax. The caterpillar vacates the old cuticle by walking backwards using first its anal prolegs. As a consequence, the old head capsule remains attached to the exuvia, which has a mediodorsal ecdysial line along the whole abdomen (Fig. 3). The process is basically the same in all larval instars, with the exception of pupation, when the method depends on the sex. In male larvae the head capsule splits along an adfrontal line of weakness (normally the left one) and the ecdysial line continues by breaking asymmetrically the prothoracic shield and then the abdomen mediodorsally (Fig. 4a). In female larvae the ecdysial line is T-shaped; the cuticle splits transversely along the posterior margin of the prothoracic shield and the ecdysial line continues mediodorsally along the thorax, reaching at most the first abdominal segment (Fig. $4 b)$.

\section{Quiescent instar}

In early or mid-summer Heterogynis larvae spin a tightly woven little cocoon ("hibernaculum") in which they pass the rest of the summer and the cold season, emerging only in late winter-early spring. The habit of diapausing in a small cocoon is also known for the larvae of Heterogynis paradoxa (cf. Chapman, 1902), and there is no reason to question that all the species of Heterogynis share the same behaviour. The shape of the hibernaculum is potentially spherical, but as it is normally hidden in crevices and plant debris, it is lenticular in shape.

In the species studied, after the completion of the hibernaculum, the caterpillar moults and enters a "quiescent instar". This does not prevent it from eating most of the exuvia ("active" larvae rarely eat exuviae, and they always avoid the sclerotized parts) and covering the pieces left with a thin layer of silk. Eventually, the larva adopts a "U"-position by curving the body extremities upwards (Fig. 5).

The external morphology of the quiescent larva is strikingly different from that of active instars. The head is completely retracted into the pro- and mesothorax, its position being easily observed in specimens treated with cold $10 \% \mathrm{KOH}$ for 2 days (Fig. 6). Only a narrow slit of the prothorax, through which the tip of the maxillae and spinneret protrude betrays its presence. The study of the head capsule requires the dissection of larvae, which reveals that the head is less sclerotized than in the active larva, but it is otherwise normal and with functional appendages. The legs are reduced, stouter than in the active instars and with very small claws. The prolegs are vestigial, hemispherical in shape, with rudimentary or no crochets at all. The prothoracic shield is seemingly normal, although only a part of it retains sclerotization, as the other part is due to epidermal coloration. The tactile setae of the trunk and legs are so short that they can hardly be discerned unless the larva is examined at a magnification of $\times 80$ or more. All setae are smooth and spine-like, even those that are plumose or spatulate in the active instars. The tactile setae of the head are slightly shorter than in active instars and their relative lengths have changed. Microsetae remain unchanged. The cuticle is detached from the body; this is strikingly apparent as tracheae can be seen leaving the body and joining the spiracles. Moreover, in the middle of the proleg plantae there is a deep cavity under the cuticle, probably representing the invaginated plantae of the following larval instar.

\section{External morphology and chaetotaxy \\ Head}

The morphology and chaetotaxy of the head of $H$. penella and $H$. eremita are very similar, the only difference being the absence of a seta in the second species (see below).

In all active instars the head capsule is heavily sclerotized and shiny black, especially around the mouthparts and antennal sockets, in the ocellar area and along the adfrontal sutures. After the first moult, the head is always kept more or less retracted. Even in specimens boiled to obtain maximum protrusion of the head, the actual junction between the neck and the head capsule could not be easily traced. In these specimens, the neck-cuticle wrapped around the posterior part of the head forms two folds. The outermost fold is transverse and nearly straight, while the second, that is the one close to the head capsule, dorsally outlines a triangle with a vertex pointing anteriorly (Fig. 7a-b). This vertex overlays the insertion of powerful, dorsal, head retractor muscles. As it is possible to insert a micropin between the two cuticular folds, and between the inner fold and the head, the folds do not represent the actual junction-line of the neck. Only the mesal part of the internal fold is definitely inserted on the cuticular ridge bordering the insertion of the dorsal head retractor muscles.

The paired dorsal head retractor muscles insert on a flat pentagonal area in the posteromedial region of the head, where normally the epicranial suture is located in other lepidopterous larvae. The adfrontal sutures converge posteriorly toward this area, without giving rise to a distinct epicranial suture (Fig. 9b). They bear the anterior tentorial pits, approximately at the same level as setae AF2.

Two posterior transparent zones are present on each side of the head, one prolonging the epicranium posteriorly, the other prolonging the gena posteriorly and ventrally (Fig. 9a-c). The latter bears an occipital sclerite, as well as the posterior tentorial pits.

No dorsal ecdysial lines are discernible except in last instar male larvae. Nevertheless, these also lack distinct adfrontal sclerites, as the whole adfrontal area is transparent. In one specimen of $H$. penella two zones with slight pigmentation of the cuticle on the right adfrontal area were observed, these possibly representing remnants of an adfrontal sclerite. 

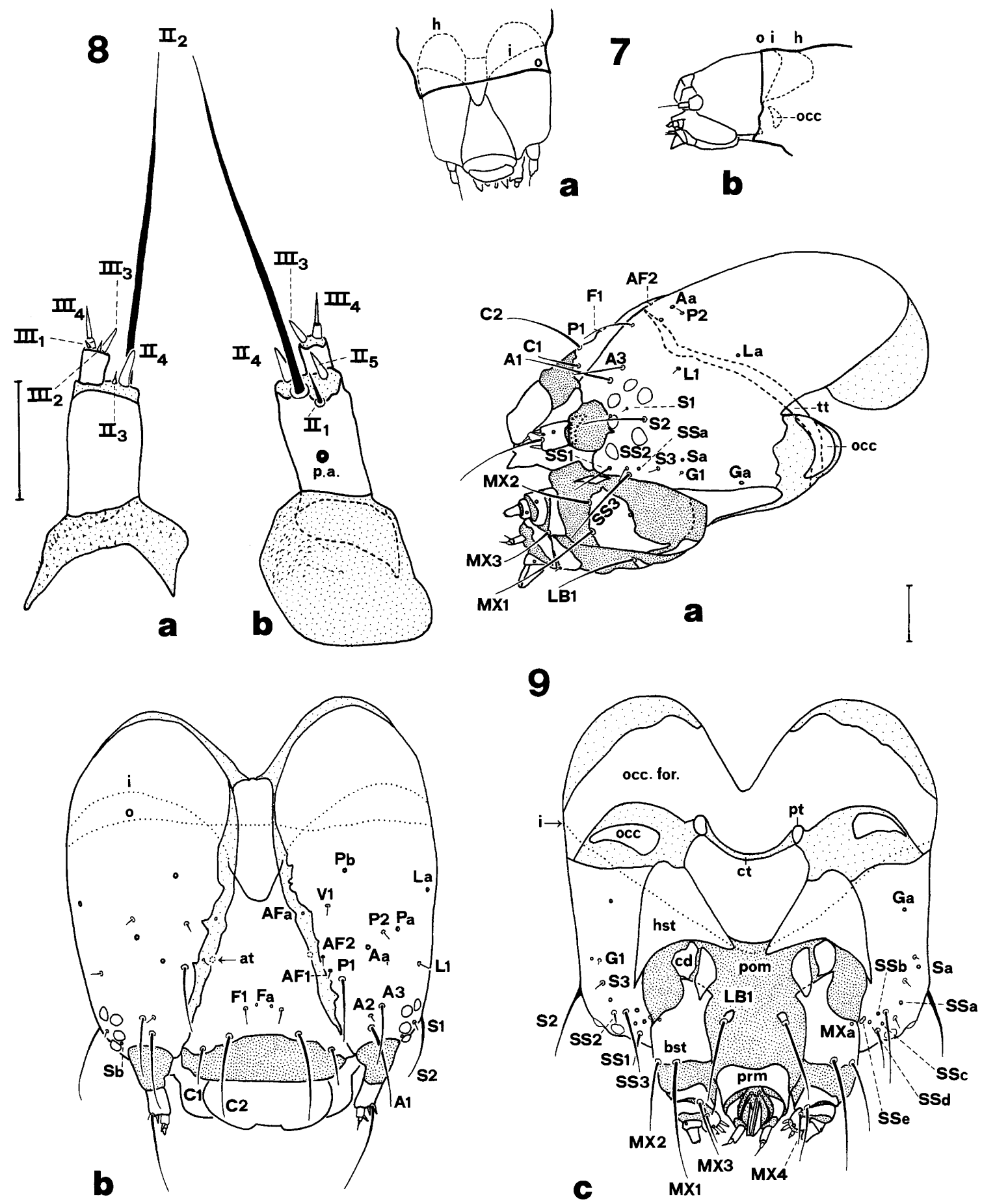

Figs 7-9. 7 - junction between head and prothorax (schematic): (a) dorsal view; (b) lateral view. Head outline (h); inner fold (i); outer fold (o); occipital sclerite (occ); 8 - antenna of H. eremita (female last instar larva): (a) medial view; (b) lateral view (membranes dotted; scale bar $=0.1 \mathrm{~mm}$ ); 9 - head chaetotaxy of $H$. penella and $H$. eremita (male last instar larva): (a) lateral view; (b) dorsal view; (c) ventral view (labral setae omitted; membranes closely dotted, unpigmented tough cuticle sparsely dotted; scale bar = $0.1 \mathrm{~mm}$ ). Anterior tentorial pit (at); basistipes (bst); cardo (cd); corporotentorium (ct); hypostomal lobe (hst); inner and outer folds of the neck cuticle (i, o); occipital sclerite (occ); occipital foramen (occ.for.); postmentum (pom); praementum (prm); posterior tentorial pit (pt); anterior tentorial arm (tt).

The border of the head capsule where the antenna articulates shows a small acute incision between stemmata 4 and 5. Six stemmata are present on both sides of the head capsule, as is normal in lepidopterous larvae, with stemma 5 slightly displaced antero-ventrally. The heavily sclerotized hypostomal lobes are subtrapezoidal in shape and separated by the occipital foramen, which is covered by the neck-cuticle (i.e., no hypostomal bridge is present) (Fig. 9c). The anterior tentorial arm is heavily sclerotized, with the exception of its proximal part. The 
corporotentorium is wholly unpigmented, while the very short posterior tentorial arms are heavily sclerotized.

\section{Chaetotaxy}

First instar larva (cf. last instar in Fig. 9a-c, the only difference being adfrontal areas not yet distinct). Clypeal setae are normally inserted on little protrusions of the frontoclypeus; $\mathrm{C} 2$ is slightly posterior to $\mathrm{C} 1$. F1 is medioposterior to $\mathrm{C} 2$. Pore $\mathrm{Fa}$ is always medial to $\mathrm{F} 1$, but its position is otherwise variable. Asymmetries are quite common, e.g. Fa being anterior to F1 on one side and posterior to it on the other. A1 is located dorsal to stemma 3. A2 is posterior and slightly dorsal to A1. A3 is dorsal to stemma 2. Pore $\mathrm{Aa}$ is posterior to the setae of the A-group and lies between AF2 and $\mathrm{Pa}$. The adfrontal pore (AFa) is posterior to the adfrontal setae. If present, the anterior adfrontal seta (AF1) is located more laterally than AF2 and close to it; it has never been observed in $H$. eremita, whereas in $H$. penella its occurrence is inconstant (very often lacking, at least on one side of the head). P1 is remarkably displaced anteriorly, being anterior to the adfrontal setae. P2 is postero-lateral to Aa, its position being often asymmetric between the sides of the head and subject to shift anteriorly or posteriorly. Pore $\mathrm{Pa}$ is variously positioned near to $\mathrm{P} 2$, and asymmetries do also occur in this case. Pore $\mathrm{Pb}$ is the most caudal dorsal sensillum of the head and it is far apart from the setae of the posterior group. $\mathrm{L} 1$ is posterior to stemmata $1-2$ and pore $\mathrm{La}$ is posterior to $\mathrm{L} 1 . \mathrm{S} 2$ is located between stemmata 1 and 6. S1 lies in the area encircled by the stemmata, nearer to stemma 3. Pore Sa is postero-dorsal to S3. Seta $\mathrm{S} 3$ is anterior to $\mathrm{Sa}$. Another stemmatal pore, $\mathrm{Sb}$, is located between the antennal socket and stemmata 3 and 4, close to the latter stemma. It is not mentioned by Hasenfuss (1980), but it is here considered homologous with McIndoo's (1929) Ob. SS1 lies near to the antennal socket, antero-ventrally to stemma 5 . SS2 and SS3 are located posterior to SS1, SS2 being posterior to stemma 5 and dorsal to SS3. Pore $\mathrm{SSa}$ is posterior to SS2, inbetween this one and $\mathrm{S} 3$. The substemmatal region bears four additional pores, not mentioned by Hasenfuss (1980). Two of them, SSb and SSc, are considered homologous with McIndoo's (1919, 1929) SOb and SOc. $\mathrm{SSb}$ is ventral to seta SS3; SSc lies half way between setae SS1 and SS3. The other two pores, here named SSd and SSe, have not seemingly been recorded in other lepidopterous larvae. SSd is ventral and aligned with SSc. $\mathrm{SSe}$ is the most ventral substemmatal pore, and it is often concealed by the stipes. SSe is a "double" pore, apparently derived from the fusion of two pores. G1 is located posterior to $\mathrm{S} 3$ and it is posterior or approximately aligned with $\mathrm{Sa}$. Its distance from $\mathrm{Sa}$ and $\mathrm{S} 3$ is variable, often being different between on each side. Pore $\mathrm{Ga}$ is well posterior to $\mathrm{G} 1$ and the distance between G1-Ga usually equals that of L1-La. Only one vertical seta, V1, is present; it is lateral to pore $\mathrm{AFa}$, hence anterior to pore $\mathrm{Pb}$. Pore $\mathrm{Va}$ is absent.

Successive larval instars. Adfrontal setae often lie outside the adfrontal areas, which in Heterogynis are clearly thinner than the adfrontalia of other Lepidoptera. Accord- ingly, adfrontal areas usually bear only the pore AFa, but can embrace (often only on one side of the head) also seta AF2. In one specimen of $H$. penella pore AFa was situated on the borderline between the sclerotized epicranium and the hyaline adfrontal area.

Relative lengths of cranial setae. The longest cranial setae (excluding those located on mouthparts and antennae) are $\mathrm{C} 2$ and $\mathrm{A} 1 ; \mathrm{P} 1, \mathrm{~S} 2$ and $\mathrm{SS} 3$ are usually slightly shorter. The third longest seta is A3; the fourth longest are $\mathrm{C} 1$ and SS1. All other cranial setae can be regarded as microsetae, except for F1 that is slightly longer. The relative lengths undergo slight changes in quiescent larvae, but $\mathrm{C} 2$ remains alone as the longest seta on the head capsule.

Supernumerary setae and pores. A supernumerary short seta was observed posterior to SS2 in one first instar larva of $H$. eremita. An additional genal pore occurred in one first instar larva of $H$. eremita and in one female last instar larva of $H$. penella. In both cases the pore was present only on one side of the head and was located postero-ventrally to Ga. One first instar larva of $H$. penella showed a microseta in place of pore $\mathrm{Fa}$, thus confirming Hasenfuss' (1963) observation of the developmental homology between setae and pores.

Antennae (Fig. 8a-b). The antennal sockets are spinulose on the medial surface, while their outer surface is smooth except for a ventral patch of tuberculate cuticle. The antennae are three-segmented, but as the membrane of the antennal sockets inserts onto the distal margin of the first segment, this one is entirely internal. The sclerite of this segment is roughly triangular and slightly arched, and only extends laterally; in first instar larvae its proximal margin bears a pore that gradually disappears by merging with the margin in subsequent instars and is always absent in last instar larvae. This pore probably represents a vestige of the sensilla of the first antennal segment (cf. Dethier, 1939: 458), as in Heterogynis it is covered by the membrane of the antennal socket. The second antennal segment is cylindrical, with a small triangular apodeme protruding proximally from its inner side. This segment bears externally a pore (p.a.) at the middle of its length or slightly displaced toward the base. Distal to that pore, on the distal margin of the sclerite, there are a long seta $\left(\mathrm{II}_{2}\right)$ (a little longer than SS3) and dorsal to it a microseta $\left(\mathrm{II}_{1}\right)$. The membrane between segments 2 and 3 bears two large, superficially sculptured sensilla basiconica, one of which $\left(\mathrm{II}_{5}\right)$ is dorsal and the other $\left(\mathrm{II}_{4}\right)$ ventral with respect to segment 3 . In between the large ventral sensillum basiconicum and the third antennal segment there is a small sensillum basiconicum $\left(\mathrm{II}_{3}\right)$ and often a small inner supernumerary sensillum basiconicum. The third antennal segment is cylindrical and bears apically a large sculptured sensillum basiconicum ( $\left.\mathrm{III}_{3}\right)$, a large smooth sensillum styloconicum (corresponding to "segment 4 plus sensillum $\mathrm{IV}_{1}$ " sensu Gerasimov, 1952, and here renamed $\mathrm{III}_{4}$ ) and two very small sensilla basiconica ( $\mathrm{III}_{1}$ and $\mathrm{III}_{2}$ ), which can only be seen when an antenna is observed from the inner side. 


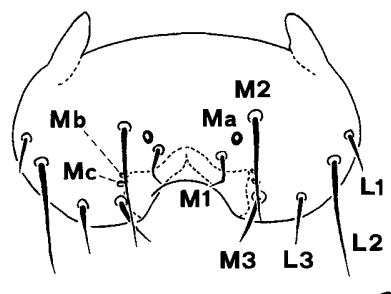

10
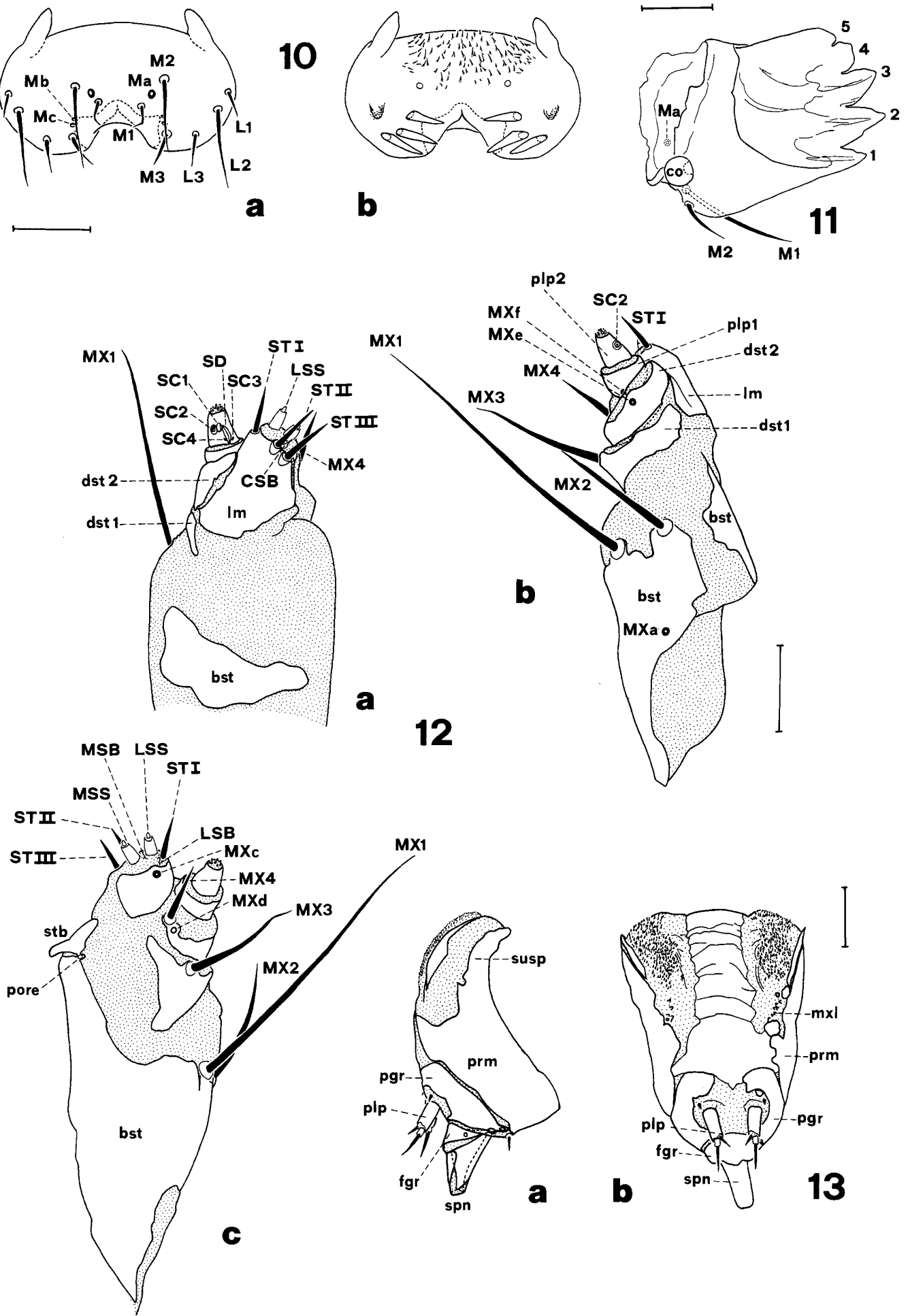

Figs 10-13. 10 - labrum of $H$. eremita (male last instar larva): (a) dorsal view; (b) ventral view (scale bar $=0.1 \mathrm{~mm}$ ); $11-$ left mandible of $H$. penella (penultimate instar larva), inner side (scale bar $=0.1 \mathrm{~mm}$ ). Mandibular condyle (co); $12-$ left maxilla of $H$. eremita (female last instar larva): (a) dorsal view; (b) lateral view; (c) ventral view (membranes dotted; scale bar $=0.1 \mathrm{~mm}$ ). Basistipes (bst); dististipes, divided into two segments (dst1, dst2); lobarium (lm); segments 1 and 2 of maxillary palp (plp1, plp2); stipital bar (stb); 13 - premento-hypopharyngeal lobe of $H$. eremita (female last instar larva): (a) lateral view; (b) dorsal view (membranes dotted; scale bar $=0.1 \mathrm{~mm})$. Fusuliger (fgr); maxillula $(\mathrm{mxl})$; palpiger (pgr); labial palp (plp); praementum (prm); spinneret (spn); hypopharyngeal suspensorium (susp).

Mouthparts. Labrum (Fig. 10a-b). The labrum of $H$. penella and $H$. eremita conforms to the generalized configuration of the labrum in lepidopterous larvae. Its distal margin is mesally concave and the proximal one bears two heavily sclerotized apodemes (tormae) that are slightly curved ventrally. No difference in the labral chae- 
totaxy was observed in the two species, or between the different larval instars of a species. The labrum bears dorsally six pairs of setae and three pairs of pores. Two long (M2 and L2) and four short setae (M1, M3, L1, L3) are present on each side. M1 is the most medial seta and lies at about two-thirds the length of the labrum from its base. M2 is located posteriorly and laterally to M1, at one-third the length of the labrum. M3 is precisely distal to M2 and lies near the distal margin of the labrum. L1, L2 and L3 are inserted near the lateral margin of the labrum. L1 is usually slightly distal to M2 (but rarely is it at the same level or even slightly proximal to it) and L2 is slightly distal to L1. L3 is as distal as M3, so that the distance L2-L3 is greater than between L1-L2. Pore Ma, corresponding to Forbes' (1910) Ia, is located half-way between setae M1 and M2. Pores Mb and Mc lie between M2 and M3, nearer to M3 and very close to each other; $\mathrm{Mb}$ is slightly medial to Mc. The epipharyngeal surface of the labrum bears three sensilla basiconica and, proximally, a sensillum campaniforme on each side. Moreover, there is a paired lateral organ, which probably has a scraping function. It consists of a small tongueshaped lamella pointing distally, which arises lateral to the sensilla. The lamella overlays a finely spinulose area of the epipharynx. The organ is well developed in $H$. eremita, whereas in $H$. penella it is greatly reduced. The epipharyngeal surface proximal to the sensilla is coarsely spinulose. An epipharyngeal shield (sensu Heinrich, 1916) is present; it is deeply notched distally, the notch being partially covered by the dorsal surface of the labrum.

Mandibles (Fig. 11). The mandible bears five teeth that, following Hasenfuss (1980), are sequentially numbered from the inferior one, i.e. the one nearest to the condylus, to the superior. Teeth 1-3 are triangular in outline and apically pointed; teeth $4-5$ are blunt, the fourth being pentagonal in outline and the fifth triangular. Two setae and one pore occur on the outer side of the mandible. The setae are close to each other, the shorter one (M2) being located on the ventro-lateral edge of the mandible and the other (M1) proximo-mesally to M2. Pore Ma lies near to the proximal margin of the mandible, at about one-third the short axis of the mandible from the ventral edge.

Maxillae (Figs 9c, 12a-c). The maxillae are linked to the labium by means of a short sclerotized stipital bar between the praementum and the distal end of basistipes. A pore, possibly homologous to McIndoo's (1919) and Gerasimov's (1952) Mxb, is present at junction between the stipital bar and the basistipes. The cardo is externally visible as a little irregular sclerite; it is dorsally produced into a long apodeme reaching the internal surface of the hypostoma. The stipes is divided into basistipes and dististipes, as usual in lepidopterous larvae. The basistipes bears a large ventral sclerite and a smaller trapezoidal dorsal sclerite. The ventral sclerite bears two setae on its distal margin and a pore (Mxa) near to the proximal margin. The mesal seta of the basistipes $(\mathrm{Mx} 1)$ is the longest seta on the head, whereas the lateral one $(\mathrm{Mx} 2)$ is about as long as SS3. The dististipes is divided into two seg- ments, as is the rule in the Ditrysia (Hinton, 1958). The first segment is an incomplete ring bearing one seta $(\mathrm{Mx} 3)$, which is usually slightly shorter than $\mathrm{Mx} 2$; the second is also an incomplete ring, which bears a short seta $(\mathrm{Mx} 4)$ on its mesal extremity and two pores, Mxd just proximo-externally to Mx4 and Mxe externally and in axis with seta Mx2. The palp consists of two segments. The first is a complete ring bearing a pore $(\mathrm{Mxf})$ on its outer side at the same level as Mxe. The second palpal segment is tronco-conical in shape and bears five sensilla on its dorsal surface and eight apical sensilla. The dorsal set of sensilla consists of a mesal, feather-shaped sensillum digitiforme (SD); two large sensilla campaniformia, the most lateral of which (SC2) is structurally more complex than the inner one ( $\mathrm{SC} 1)$, being composed of an external ring that encircles a membranous zone with a little sclerite in the middle, and two small sensilla campaniformia (SC3 and SC4), located on both sides of the base of SD. Apical sensilla are all alike when viewed under a light microscope; they appear as sensilla basiconica, one of which lies in the middle of the apical membrane encircled by the remaining seven. The maxillary lobe is encircled by a sclerite that is open mesally and much wider dorsally than ventrally. The sclerite bears ventrally a pore $(\mathrm{Mxc})$ near to its distal margin, and dorsally one normal (STI) and two modified strongly sclerotized setae (STII and STIII) on its distal margin. On the apical membrane of the maxillary lobe there are two sensilla styloconica (MSS and LSS) and three small sensilla basiconica (LSB, MSB and CSB).

Labium and hypopharynx (Figs 9c, 13a-b). The postmentum bears paired long setae (LB1) and its surface is sclerotized to a variable extent. Two roughly triangular sclerites mesal to the cardines, as well as two sclerotized areas at the base of the setae, are always present. A triangular, medial plate (non represented in the figures) is often present proximal to the setae. The premental sclerite is an incomplete ring, the open dorsal extremities of which are prolonged posteriorly into two bars (hypopharyngeal suspensoria) that sustain the membranous hypopharyngeal surface. A pair of microsetae is present medio-ventrally on the membrane between the praementum and the palpigera, and another pair dorsally between the palpiger and the palpus. Each palpiger bears two pores close together on its ventral edge, and is fused to the praementum by means of a thin ventral process. The spinneret is supported by a sclerotized ring (fusuliger) that laterally bears paired pores. The spinneret is of the tubular type (cf. Epstein, 1996) and has four distinct sclerites, i.e. a pair of triangular lateral sclerites and two unpaired sclerites, one dorsal, and one ventral and rod-like. Labial palps are two-segmented; the distal segment is displaced ventrally with respect to the axis of the palp; each palpal segment bears a short seta. The seta on the basal segment originates from the apical membrane of the segment and is shorter than the seta on the second segment. The hypopharyngeal surface is mesally smooth and slightly sclerotized, with weak transverse folds. Both sides of the hypopharynx are membranous and bear ante- 

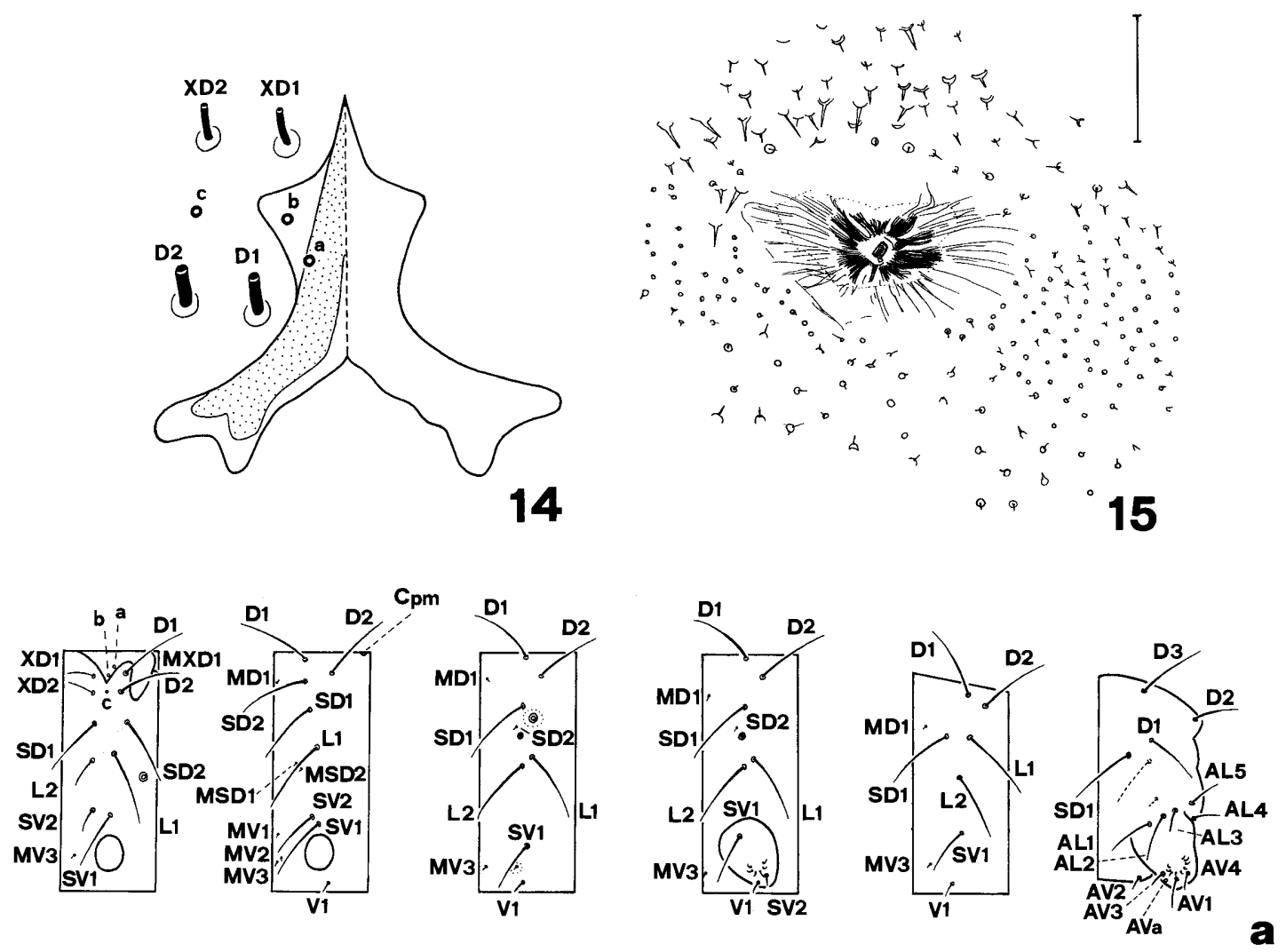

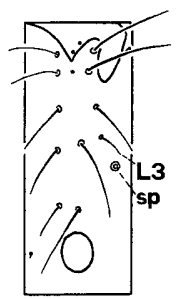

T1

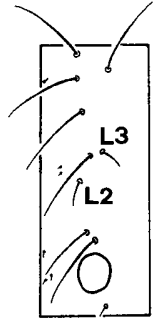

T2-T3

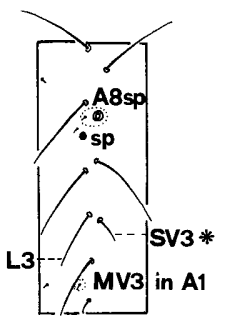

A1-A2

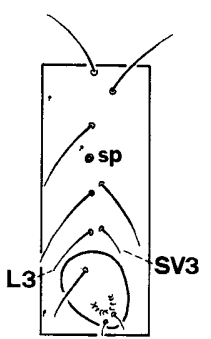

A3-A6

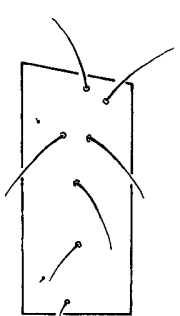

A9

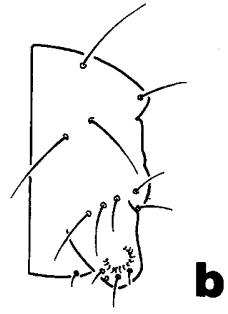

A10 16

Figs 14-16. 14 - prothoracic shield (schematic) (dotting represents zone of heavier sclerotization, setae cut near base); 15 - Chapman's organ in H. penella (first instar larva) (scale bar $=0.02 \mathrm{~mm}$ ); 16 - setal maps of thorax and abdomen of $H$. penella and $H$. eremita: (a) first instar larva; (b) second instar larva (supernumerary setae dashed). Chapman's organ (Cpm); spiracle (sp); A8sp denotes position of SD2 and spiracle on A8; MV3 in A1 denotes position of this microseta in A1; * recalls absence of SV3 on A8.

riorly a longitudinal group of sclerotized teeth (more numerous and sharp in $H$. penella, fewer and blunt in $H$. eremita), probably representing vestigial maxillulae (sensu Gryse, 1915). The membranous lateral surface of the hypopharynx is posteriorly covered with minute, slender, unsclerotized spinules.

Supernumerary setae on the mouthparts. A microseta was found near the base of the labral seta L1 in a specimen of $H$. penella; a short seta was found laterally on the membranous distal part of the basistipes in another larva of the same species. A short seta was found on the posterior border of the palpiger in a penultimate instar larva of $H$. eremita. In all these cases the supernumerary seta was present only on one side of the head.

\section{Thorax}

The prothorax is characterized by the quite unusual shape of the prothoracic shield (Fig. 14), that is reminiscent of a triangle with one of the vertices pointing towards the epicranial notch. From its sides arise an anterior lateral lobe and a posterior branch. The cuticle of the shield and between the lateral lobe and the posterior branch is devoid of spinules. The base of the triangle bears a median incision, feeble in the first instar and more pronounced in successive instars. The sclerotization of the prothoracic shield is heavier along a $\mathrm{V}$-shaped area inner to the triangle, and this area is the only distinctly sclerotized part of the shield in quiescent larvae. The $\mathrm{V}$-shaped area does not include the lateral lobes, the medial posterior part and the apex of the posterior branches of the sclerite. The shape of the prothoracic 
shield undergoes little change during larval development and in a given instar differs slightly between the two species.

Another interesting feature of the thorax is the presence, restricted to the first instar larva, of an odd sclerite located medio-dorsally on the mesothorax, near to the intersegmental membrane with the metathorax. Chapman (1898) was the first to observe this little sclerite, but did not formulate any hypothesis about its function. The sclerite lies on one of the few cuticular zones that are free of spinules, as the cuticle surrounding it only shows radial folds. The sclerite always lies on a slight tronco-conical protrusion of the cuticle, and a small pit is apparent at its very centre (Fig. 15). Whether this pit is sensory or the opening of a glandular duct is still open to debate. The name "Chapman's organ" is here proposed for this organ. Differences in the configuration of the organ occur in the two species. In fact, in $H$. penella the sclerite is surrounded by an area that is also sclerotized, albeit more weakly than the sclerite itself, while in $H$. eremita such peripheral sclerotization is lacking. The shape and size of the central sclerotized area can vary from specimen to specimen within the same species, and there is no evidence of any constant difference between the species.

Otherwise the thorax of Heterogynis larvae has the normal appearance of the thorax of generalized lepidopterous larvae, with three pairs of legs, nearly identical to each other, and a pair of functional spiracles on the prothorax. A pair of spiracular rudiments on the anterior margin of the metathorax is discernible.

\section{Chaetotaxy}

No differences were observed between Heterogynis penella and $H$. eremita in the shape and position of thoracic setae and pores.

First instar larva (Fig. 16a). Prothorax. Pores. Pore b is located on the lateral lobe of the prothoracic shield, more or less half way between setae XD1 and D1. Pore a is located on the more sclerotized area of the shield, dorsoposteriorly to pore $\mathrm{b}$. Pore $\mathrm{c}$ lies outside of the prothoracic shield, half way between setae XD2 and D2, and is ventral to pore $b$.

Proprioceptors. MXD1 is posterior to the prothoracic shield, near to the base of the posterior branch of the shield and opposite, but slightly dorsal, to mesothoracic MD1. MV2 is lacking. MV3 is anterior to the coxal articulation, and much closer to the anterior margin of the prothorax than to the base of leg.

Tactile setae. XD1 is anterior to the lateral lobe of the prothoracic shield; XD2 is in axis and ventral to XD1. These two setae are distinctly thinner than all other tactile setae on the body. D1 and D2 lie posterior to XD1 and $\mathrm{XD} 2$, respectively. SD1 is inferior and in axis with XD2 and SD2 posterior to SD1. L1 is located inferior to SD1 and SD2, a little nearer to SD2. L2 lies along the same vertical axis as $\mathrm{XD} 1, \mathrm{XD} 2$ and $\mathrm{SD} 1$; it is inferior to SD1 and antero-ventral to L1. SV1 is just superior to the coxal articulation, SV2 anterior and a little more superior to
SV1, lying in the same line as XD1, XD2, SD1 and L2. $\mathrm{V} 1$ is lacking.

Meso- and metathorax. As normal for lepidopterous larvae, no differences were observed between these two segments as regards the chaetotaxy. Proprioceptors. MD1 is located near to the anterior margin of the segment and is slightly ventral to SD2. MSD1 and MSD2 are adpressed to each other and extraordinarily antero-ventral to seta L1, MSD1 is antero-dorsal to MSD2. MV1, MV2 and MV3 are located in front of the coxal articulation, nearer to the anterior margin of the segment than to the coxa. MV1 is anterior and slightly ventral to seta SV1. MV1 and MV3 lie on the same vertical line, while MV2 is between and a little posterior to them. MV2 is nearer to MV3 than to MV1.

Tactile setae. D1 is antero-dorsal to D2. SD2 is inferior and in axis with D1; SD1 is inferior and slightly posterior to SD2. L1 is ventral and slightly posterior to SD1. The two subventral setae are adpressed to each other and located near to the dorsal margin of the coxal articulation, SV1 being postero-ventral to SV2. V1 is postero-ventral to the coxal articulation.

Second instar larva (Fig. 16b). Prothorax. The subprimary L3 is posterior and slightly dorsal to L1.

Meso- and metathorax. L2 and L3 appear after the first moult. L3 is very close and postero-dorsal to L1; L2 is located antero-ventrally to L1.

Successive larval instars. No secondary setae are present. In the quiescent instar all the tactile setae become greatly reduced in length; they are, however, still longer than microsetae.

Relative lengths of thoracic setae. Prothorax. In first instar larvae the longest tactile setae are D1, D2, L1, SD1, SD2 and SV1, all of the same length. The second longest are XD1, XD2, L2 and SV2. In second instar larvae the longest tactile setae are D1, D2 and L1, followed by SD1 SD2, L2, and SV1. The third longest are XD1, XD2, SV2 and L3, but the last seta increases in length at successive moults and nearly attains the length of L1 in last instar larvae.

Meso-and metathorax. In first and second instar larvae, the longest tactile setae are D1, D2, SD1, SD2, L1 and SV1, all slightly longer than prothoracic D1. The second longest are SV1 and SV2. The third longest are the subprimaries L2 and L3, which are as long as prothoracic L3. The shortest seta is V1. The subprimaries L2 and L3 increase in length at successive moults, so that in last instar larvae they almost attain the length of L1.

Legs (Fig. 17a-d). The legs are nearly identical in appearance, with the exception of the first pair being a little smaller. The coxal sclerite is triangular, covering only the anterior side of the coxa and bearing setae $\mathrm{Cx} 1$, $\mathrm{Cx} 2$ and $\mathrm{Cx} 3$. A pair of apodemes connect the coxa and the trochanter anteriorly. $\mathrm{Cx} 2$ is the longest seta of the leg and it is plumose in contrast to the others. $\mathrm{Cx} 1$ and $\mathrm{Cx} 3$ are microsetae and are particularly close to $\mathrm{Cx} 2 . \mathrm{Cx} 4$, $\mathrm{Cx} 5$ and $\mathrm{Cx} 6$ are located on a medial prominence of the coxa, Cx6 being longer than the other two setae. $\mathrm{Cx} 7$ and $\mathrm{Cx} 8$ lie on the posterior side of the coxa; $\mathrm{Cx} 7$ is as long 


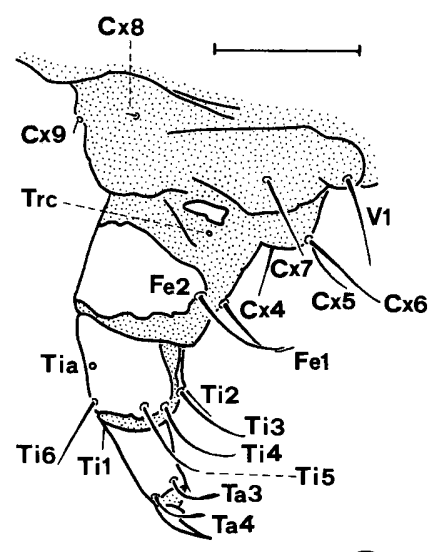

a

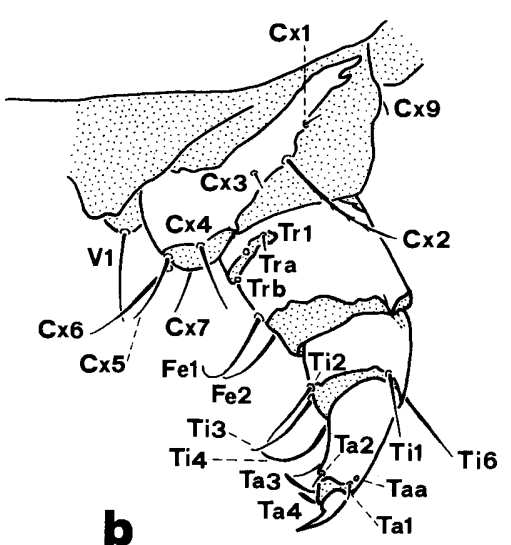

17
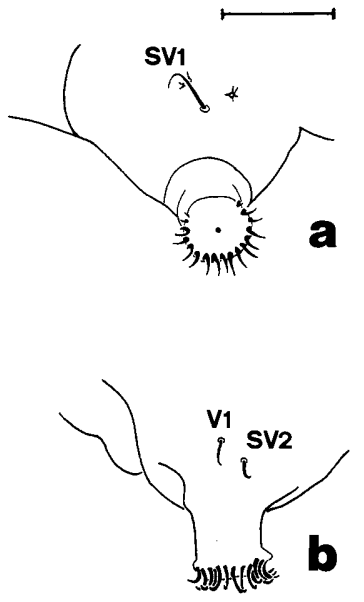

18
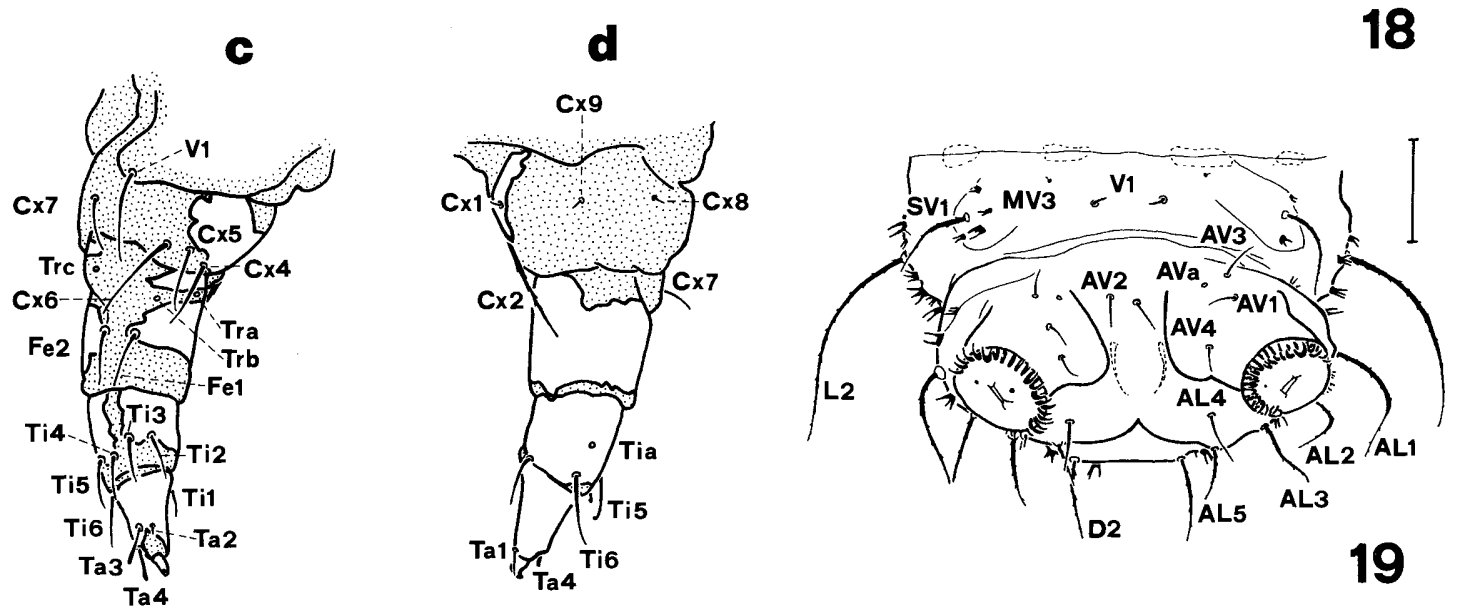

Figs 17-19. 17 - left mesothoracic leg of H. penella and H. eremita (last instar larva): (a) posterior view; (b) anterior view; (c) inner view; (d) outer view (membranes dotted, scale bar $=0.5 \mathrm{~mm}$ ); 18 - prolegs of abdominal segment 3 of H. eremita (fifth instar larva): (a) left proleg, outer view; (b), right proleg, inner view (scale bar $=0.3 \mathrm{~mm}$ ); 19 - posterior end of last instar larva of $H$. penella, ventral view (scale bar $=0.5 \mathrm{~mm}$ ); dashed lines encircle cuticular zones devoid of spinules.

as $\mathrm{Cx} 4$ while $\mathrm{Cx} 8$ is a microseta. Rarely an additional microseta ( $\mathrm{Cx} 9)$ is present on the outer side of the coxa, half way between $\mathrm{Cx} 8$ and $\mathrm{Cx} 1$. The trochanter bears anteriorly a sclerite partially fused with the femur and posteriorly a free sclerite. On the membranous area of the trochanter there are a microseta $(\operatorname{Tr} 1)$ and three pores (Tra, Trb and Trc). The first pore is located just distal to the origin of the trochanteral apodeme and can be embraced by an extension of the trochanteral sclerite. The femoral sclerite has the form of an incomplete ring that is open mesally. Two setae (Fe1 and Fe2), equally long, are located at both ends of the incomplete ring. The tibial sclerite is also in form of an incomplete ring that is open mesally and bears six setae on its distal margin and a pore. Setae Ti2-Ti5 are located on the inner side of the sclerite; Ti2 and Ti3 are anterior to the mesal membranous area, while Ti4 and Ti5 are posterior to it. Ti3 and Ti4 may be spatulate (usually not on all legs of a specimen). Setae Til and Ti6 are inserted on the outer side of the tibia; pore Tia is located proximal to seta Ti6, right in the middle of the sclerite. The tarsal sclerite is conical with the distal margin deeply notched mesally. Four setae are inserted on the distal margin of the sclerite. The ante- rior ones (Ta1 and Ta2) are microsetae, while the posterior ones (Ta3 and $\mathrm{Ta} 4)$ are longer and usually spatulate (especially in $H$. penella). The spatulate shape is more evident in first instar larvae and becomes less pronounced during development; the two setae are never spatulate in quiescent larvae. A pore (Taa) is present just proximal to Ta1. The pretarsus bears a globular axial seta (sensu Epstein, 1996). The apex of the claw extends beyond the base of pretarsus. Quite commonly one or more leg setae can be absent, noticeably $\mathrm{Cx} 7$ and one of the two femoral setae.

\section{Abdomen}

The abdomen bears spiracles on segments A1-A 8 and prolegs on segments A3-A6 and A10. The last segment is devoid of accessory structures linked to the anal opening, like anal fork, anal comb and frass flippers.

\section{Chaetotaxy}

First instar larva (Fig. 16a). Segments A1-A9. Proprioceptors. MD1 is present on A1-A9, on A1-A8 in the same position as on meso- and metathorax and on A9 being slightly displaced ventrally. It is, however, markedly 
dorsal to $\mathrm{SD} 2$, as this seta is much more ventrally positioned than on the thorax. MV3 is present on A1-A9; it lies near to the anterior margin of the segment at a height intermediate between those of SV1 and V1, except for A1, where it is strongly displaced posteriorly, being nearly aligned with SV1 and V1.

Tactile setae. D1 and D2 are in the same position as on the meso- and metathorax. SD1 is ventral to D1, the two forming a vertical alignment, except on A9, where SD1 is antero-ventral with respect to $\mathrm{D} 1 . \mathrm{SD} 2$ is present on A1-A8 and, as a rule, transformed into a microseta that lies just antero-dorsally to the spiracle (antero-ventrally on A8, due to the dorsal displacement of the spiracle). On A1-A8, L1 and L2 are close to each other, L2 being vertically aligned with D1 and SD1 and antero-ventral to L1. On A9, L1 is more dorsally positioned, nearly reaching the same level as SD1. SV1 is present on A1-A9 and on A3-A6 it lies on the outer side of the proleg. On A1-A2 and A7-A8, SV1 is half way from the margins of the segment. SV2 occurs only on the proleg-bearing segments, and it is inserted on the inner side of the proleg. V1 is close to the midventral line, except for the proleg- bearing segments, where it lies on the inner side of the proleg.

Second instar larva (Fig. 16b). L3 is subprimary on A1-A8 and never occurs on A9. It is located half way between L2 and SV1. SV3 is subprimary on A1-A7 and absent on A8-A9. It is posterior and very close to L3, slightly ventral to it on A1, A2 and A7, and a little dorsal to it on the proleg-bearing segments. Probably, Dyar's (1895) observation that in Heterogynis "vi", viz. L3, is represented by two setae relates to the closeness between L3 and SV3.

Successive larval instars. No further changes occur in the chaetotaxy of the abdomen in successive larval instars. As mentioned above, in the quiescent instar all the tactile setae are very short.

Relative lengths of A1-A9 setae. The relative lengths of some abdominal setae change during development. In particular, subprimary setae grow longer after the second instar. In first and second instar larvae, the longest tactile setae are D1, D2, SD1, L1 and L2, all as long as the mesothoracic D1. The second longest are SV1 and the subprimary L3 that are equal in length to the mesothoracic SV2; the fourth is the subprimary SV3, that is as long as the thoracic L3. The shortest tactile setae are SV2 and V1 that are as long as the thoracic V1. In last instar larvae, SV3 is as long as SV1, and L3 is intermediate in length between SV1 and L1.

Anal segment (Figs 16a-b, 19). Anal shield absent. Only primary setae are present. The most dorsal seta is D3. D1 is ventral to D3. D2 is postero-ventral to D3 and postero-dorsal to D1. SD1 is antero-ventral to D1. The AL-group borders the base of the proleg externally and posteriorly. The most anterior seta is AL1, followed by AL2, AL3 and AL4, AL5 being dorsal to AL4. Pore ALa is absent. The proleg bears the AV-group on its inner side; AV3 is the most anterior, followed by AV1 and AV4. Also the pore AVa lies on the inner side of the proleg, between AV3 and AV1 and proximal to the
AV-setae. Seta AV2 occupies the same position as V1 on the other abdominal segments.

Relative lengths of A10 setae. In first instar larvae the longest setae are D1, D3 and SD1, which are as long as the prothoracic D1. The second longest are AL1 and AL2; the third longest D2, AL4, AL5 and AL3, the last one often a little longer than the others. The shortest setae are AV1, AV2, AV3 and AV4, with AV1 occasionally a little longer than the others. In second instar and older larvae D3 often becomes comparatively shorter, as long as AL1 and AL2; also AL5 and AL4 become shorter, as long as the AV setae.

Supernumerary setae. In a few larvae, supernumerary setae (or only their papillae) were found on one side of segment A10. These supernumerary setae were located on one or both of the two positions shown in Fig. 16a.

Prolegs (Figs 18a-b, 19). Crochets arranged in a mesal, uniordinal and uniserial partial circle. One or two crochets at both ends of the series are usually smaller than the others. Crochet number increases during development, from a minimum of 4-6 (7-9 on anal prolegs) in first instar larvae to a maximum of $21-28$ in last instar larvae. In the early instars the anal prolegs bear a higher number of crochets than the other prolegs, but this difference gradually disappears during development. Crochet number is highly variable and heterolateral prolegs often bear different numbers of crochets. A small hemispherical sclerotized prominence (rarely two or more) may occur in the middle of the planta. It does not correspond internally with the insertion of the plantar retractor muscle, in contrast with Bollmann's (1955) findings on the larvae of some Crambidae. This prominence may occasionally be transformed into a supernumerary crochet on one or more prolegs, this recalls Gerasimov's (1952) theory on the origin of crochets from cuticular granules.

\section{DISCUSSION}

The absence of clearly defined autapomorphies for the Zygaenoidea, the likely involvement of several family groups with very different habitus, life-styles and evidence of synapomorphies linking just a few of these groups, led to a growing interest in this superfamily as a test group for phylogenetic analyses (Minet, 1986; Scoble, 1992; Miller, 1994; Geertsema et al., 1996; Epstein et al., 1999; Naumann et al., 1999; Yen, 2003). As a consequence, a number of family groups were recently excluded from the Zygaenoidea (e.g. Charideinae), included (e.g. Lacturidae), or underwent changes in their delimitation and supposed relationships (e.g. Aididae, Chrysopolomidae, Lacturidae, "Phaudinae") (Common, 1970, 1990; Minet, 1991; Heppner \& Inoue, 1992; Heppner, 1993, 1995; Epstein, 1996; Epstein et al., 1999; Fänger et al., 1999). Nevertheless, the monophyly of the Zygaenoidea is still being debated. For example, it has not yet been assessed whether they should include the two assemblages that have been traditionally called the "Zygaenid-group" (Zygaenidae, Anomoeotidae, Himantopteridae, Lacturidae, Heterogynidae) and "Limacodid-group" (Limacodidae, Chrysopolomidae, 
Dalceridae, Cyclotornidae, Epipyropidae, Megalopygidae, Aididae, Somabrachyidae). Moreover, there are different opinions over the characterisation of these families and their placement in the two groups (e.g. Brock, 1971; Common, 1970, 1975; Heppner, 1984, 1993, 1995; Heppner \& Inoue, 1992; Scoble, 1992; Geertsema et al., 1996; Epstein et al., 1999; Fänger et al., 1999).

Unfortunately, these families are not equally well known, and resolution of the phylogenetic relationships of the lesser-known is fundamental for a satisfactory definition of the Zygaenoidea. Within this framework, the position of the Heterogynidae is crucial as they share characters (symplesiomorphies?) with more primitive groups such as the Tineoidea (cf. Brock, 1971) and might be basal to the Zygaenoidea. A review of the larval traits of Heterogynis of potential phylogenetic value is therefore presented here.

\section{Autapomorphies}

Only a presumptive autapomorphy has been found for the Heterogynidae in larval morphology, viz. the presence of two primary setae on the inner side of A3-A6 prolegs. The normal condition in lepidopterous larvae is for only one seta (V1) on the inner side of the proleg (Hinton, 1946; Hasenfuss, 1963). As SV1 occurs in its usual position on the outer side of the proleg and both setae on the inner side are primary and shorter than SV1, there is evidence that the additional seta is SV2 (cf. Hinton, 1946; Hasenfuss, 1963). In fact, it is exclusively associated with the proleg and does not occur on the abdominal segments devoid of prolegs, as is the case in the most part of the Glossata (Hasenfuss, 1963). As the closest seta to the midventral line is by rule $\mathrm{V} 1$, the nearest seta to the proleg planta is here identified as SV2. In first instar larvae of Zygaena carniolica (Scopoli, 1763) (Zygaenidae Zygaeninae) there are two setae on the outer side (SV1, SV2) and one (V1) on the inner side of the proleg (pers. obs.) as occurs in Z. trifolii (Esper, 1783) (Tremewan, 1985); the additional seta found on the inner side of the proleg in non-first instar larvae of Zygaena sp. (Gerasimov, 1952; Epstein et al. 1999) and Z. filipendulae (Linnaeus, 1758) (pers. obs.) is therefore probably subprimary.

\section{"Zygaenoid" traits of Heterogynis}

Rectractile head. This is considered an autapomorphy of the Zygaenoidea (Minet, 1986). Nevertheless, no detailed anatomical study of the skeletal and muscular structures responsible for head retractability has ever been attempted. As a matter of fact, a retractile head is known in other lepidopterous superfamilies and there is no information allowing one to distinguish between homologous and homoplasious structures. Most larvae with a retractile head share concealed life-habits, as leaf-miners or stemborers. Among these are the Cossidae (cf. Gerasimov, 1952: 35), which according to the most recent classifications of the Ditrysia (Minet, 1991; Kristensen \& Skalski, 1999), make up with other Cossoidea and Sesioidea the most probable sister group of the Zygaenoidea. Nevertheless, noticeable exceptions to the relationship between head retractability and concealed feeding style are the Zygaenoidea themselves, and the Psychidae (Tineoidea) (Kozhanchikov, 1956; Davis, 1987a). Concerning the morphology of the epicranial notch, a structure nearly identical to that of Heterogynis occurs in first instar larvae of Z. carniolica (pers. obs.) and is apparent in Yen \& Horie's (1997: 44) illustration of Pryeria sinica Moore, 1877 (Zygaeninae). A similar structure was described by Grandi $(1930,1931)$ in Parahypopta caestrum (Hübner, [1808]) (Cossidae). He regards the configuration of the epicranial notch in larvae of $P$. caestrum as extraordinary, as a similar structure does not occur in other cossid larvae with stem-boring habits (e.g. Cossus cossus (Linnaeus, 1758) and Zeuzera pyrina (Linnaeus, 1761)). According to Grandi (1931), the peculiar shape of the epicranial notch allows the anterior displacement of the dorsal head retractor muscles, so that they act antagonistically to the ventral ones. This enables the head of larvae of $P$. caestrum to act as a wedge when they force their way through the soil.

Larval heteromorphosis. Heteromorphosis, i.e. difference in the types of setae or degree of spinosity between the first and subsequent instars (cf. Epstein, 1996), is recorded by Common (1990) in the Limacodidae, Epipyropidae and Cyclotornidae, and deemed to represent a zygaenoid trait. Heterogynis larvae can be regarded as heteromorphic as the coronetted tubercles appear after the first moult. However, should the homology of the cuticular processes in the Zygaenoidea be confirmed, this would be a more reliable evidence for phylogenetic relationship than the heteromorphic process per se.

Adfrontal setae. There are three setae and a pore near or inside the adfrontal area. The pore is clearly AFa, and the most posterior seta is AF2. More uncertain are the identities of the other two setae. Because of the variable presence of the middle seta (absent in H. eremita and often lacking on one side of the head in $H$. penella), it could be regarded as a new formation and the most anterior seta identified as AF1. This hypothesis leads one to assume that the most posterior seta on the epicranium is $\mathrm{P} 1$, all the V-setae being absent. A comparison with the head chaetotaxy of Aglaope infausta (Linnaeus, 1767) (Zygaenidae: Chalcosiinae) (cf. Fänger \& Naumann, 2001), Z. carniolica (pers. obs.) and Phauda mimica Strand, 1915 ("Phaudinae") (cf. Fänger et al., 1999), where all three $\mathrm{V}$-setae are present, however, shows this interpretation to be erroneous. In $Z$. carniolica the likely homologous seta of "AF1" is laterally displaced from the adfrontal area, which agrees with the identification of this seta as P1 in P. mimica Strand, 1915 by Fänger et al. (1999) and A. infausta by Fänger \& Naumann (2001). In $A$. infausta all three $\mathrm{V}$-setae are anterior to pore $\mathrm{Pb}$, in $P$. mimica V1 and V2, while in $Z$. carniolica only V1 is anterior to $\mathrm{Pb}$. Accordingly, in Heterogynis the seta regarded previously as "P1" is probably $\mathrm{V} 1$, its position anterior to $\mathrm{Pb}$ being insufficient to invalidate this hypothesis. To summarize, the anterior of the three setae associated with the adfrontal area in Heterogynis is P1, the middle one is AF1 and the posterior one is AF2; the 
most posterior epicranial seta is V1, V2 and V3 being absent. Incidentally, a similar condition is also found in $Z$. trifolii, although the seta immediately anterior to $\mathrm{Pb}$ was erroneously identified as P2 instead of V1 (Tremewan, 1985: fig. 52). This led to the assumption of a supplementary seta (O3) being present in addition to G2, an interpretation possibly resulting from Hinton's (1946: 7) illustration of Hepialus humuli (Linnaeus, 1758). Nevertheless, Hasenfuss (1969) demonstrated that the monotrysian and exoporian G2 and the dytrisian O3 are homologous and therefore cannot cooccur. Therefore, it must be concluded that Tremewan's (1985) P2 is V1 (hence V1 and V2 become V2 and V3, respectively), L1 is $\mathrm{P} 2$ and $\mathrm{O} 3$ is L1. The main outcome of the current interpretation is that the presence of AF1 is very inconstant in Heterogynis. It should be noted that the position of AF1, if present, is very similar to that in A. infausta and the single AF seta occurring in the other two Zygaenid species considered, Zygaena trifolii and Z. carniolica, should be better regarded as AF2, as based on the lability of AF1 in Heterogynis. Hence, the position of AF1 is similar in the Heterogynidae, Zygaenidae and "Phaudinae", while its tendency to be absent seemts to be a common trait only to the Heterogynidae and Zygaenidae. Another outcome is the considerable anterior shift of some dorsal head setae in the Heterogynidae, Zygaenidae and "Phaudinae". This causes P2 and even $\mathrm{V} 1$ (V1 and V2 in $P$. mimica and all the V-setae in $A$. infausta) to lie anterior to $\mathrm{Pb}, \mathrm{AF} 2$ anterior to $\mathrm{AFa}, \mathrm{A} 3$ and also P1 anterior to Aa, and (only in Heterogynis) S3 anterior to $\mathrm{Sa}$, states that rarely occur in non-zygaenoid outgroups and never all together (cf. Heinrich, 1921; Hinton, 1946; Hasenfuss, 1963, 1969). Fänger \& Naumann (2001), on the basis of the occurrence of this combination of characters in both $A$. infausta and P. mimica, suppose that this feature, together with the shortening of some head setae, "will probably prove to be a complex autapomorphic syndrome of the Zygaenoidea". In fact, setal migration is very probably related to head retractability, but only single setae or small setal groups shift anteriorly in other taxa with a retractile head. On the other hand, the shortening of head setae is a well-known phenomenon occurring in species with a retractile head (Hasenfuss, 1969).

Stemmatal setae. In lepidopterous larvae S1 is normally a macroseta, albeit shorter as a rule than S2. Excluding some groups of leaf-miners, the condition in which $\mathrm{S} 1$ is transformed into a microseta is apparently shared only between Heterogynis and some zygaenoid families, viz. Limacodidae (including Chrysopolominae), Aididae, Megalopygidae, Somabrachyidae and Zygaenidae (Tremewan, 1985; Epstein, 1996; Yen \& Horie, 1997; Fänger \& Naumann, 2001). As regards the condition of S2 in the Zygaenoidea, it is macroscopical only in the Heterogynidae, Zygaenidae and "Phaudinae", a microseta in Megalopygidae, Aididae and Somabrachyidae, and absent in the Limacodidae (including the Chrysopolominae) and Dalceridae (Epstein, 1996; Epstein et al., 1999; Fänger et al., 1999).
Cuticular cavities. Cuticular cavities for storing cyanoglucosides are present in the Heterogynidae and Zygaenidae, with the exception of the Procridinae (Epstein et al., 1999; Fänger et al., 1999; Fänger \& Naumann, 2001). It was not possible to get larvae to discharge their defensive secretion in this study, although this phenomenon was observed by Guenin (1997a). The openings of the cuticular cavities in Heterogynis are inside the coronetted tubercles. These cuticular processes increase in number during larval development; however, in the second instar, when they first appear, they are located only on the median third of the segments along with most of the setae. Naumann \& Povolný (1987) identified two types of cuticular cavities in Zygaena trifolii: (type I) large cavities, located only on the anterior and posterior thirds of the segments (outside the zones covered by macrosetae), and (type II) small cavities, distributed over the whole trunk with the exception of the ventral surface. The cuticular cavities in Heterogynis could be homologous with the small cavities in Zygaena Fabricius, 1775, this is corroborated by the difficulties encountered by Naumann \& Povolný (1987) in obtaining a discharge of the defensive secretion from these cavities, whereas the large cavities promptly released the secretion. Moreover, in Neurosymploca Wallengren, 1858 (Zygaenidae) the openings of the type II cavities are located on cone-like tubercles (Bode \& Naumann, 1987), and in Pryeria sinica (Zygaenidae) on "specialized trichomes" (Naumann \& Feist, 1987), which are strongly reminiscent of coronetted tubercles but have only one long branch. As defensive droplets from the dorsum of larvae are also known in the Limacodidae, Dalceridae and Lacturidae (Common, 1990; Epstein, 1996, 1997), Fänger et al. (1999) call for further research on the phylogenetic value of this character.

Coronetted tubercles. These have also been recorded from other species of Heterogynis (Chapman, 1904). It is uncertain whether homologous structures occur in other Zygaenoidea. Minet (1986) states that they are comparable to those of some Zygaenidae (Procridinae). Efetov \& Tarmann (1999) record these tubercles only in Adscita Retzius, 1783 and Jordanita Verity, 1946. Efetov (1994) describes the tubercles of Adscita minna Efetov, 1991 as having one central and 5-9 radially arranged spines. Nevertheless, the Procridinae lack the cuticular cavities that are known to occur in the Zygaeninae and Chalcosiinae (Naumann et al., 1999; Fänger \& Naumann, 2001), the openings of which lie in the coronetted tubercles in Heterogynis. Chapman (1894) and Christensen (1950) describe the rapid evagination of spines in newly hatched larvae of Apoda limacodes (Hufnagel, 1766) (Limacodidae). The apex of the spines, that is the only apparent part before evagination, bears a sclerotized coronet, quite reminescent of the coronetted tubercles of Heterogynis larvae. However, the tubercles of Heterogynis are more numerous and differently arranged than in Apoda Haworth, 1809.

Presence of a single MV-seta on the prothorax. Seemingly this condition has not been recorded in free-living 
caterpillars outside of the Zygaenidae. The identification of this seta as MV3 is based on its position relative to those of the MV-setae on the meso- and metathorax, being more distant from the base of the leg and a little more mesal than MV2. Tremewan (1985) also identified the MV seta on the prothorax of $Z$. trifolii as MV3, while Fänger \& Naumann (2001) regarded it as MV2 in $A$. infausta.

$\mathrm{Ta} 3$ and Ta4 spatulate. Ta3 and Ta4 are similarly modified and often more so in most Zygaenidae (Fänger \& Naumann, 2001: as Ta2 and Ta3; Yen, 2003), as they are fan-shaped in some species of Zygaena (Hasenfuss, 1999). Some Zygaenidae show only one spatulate tarsal seta (Stehr, 1987b). One or more spatulate tarsal setae also occur in the early instars of Somabrachyidae and Megalopygidae, but as based on Epstein's (1996: 48) illustrations the joint condition of Ta3-Ta4 spatulate and Ta1-Ta2 hair-like does not occur. The Aididae, Dalceridae, and Limacodidae do not have spatulate tarsal setae (Epstein, 1996). A single spatulate seta (Ta4) occurs in the isolated genus Phauda Walker, 1854 (Fänger et al., 1999: as Ta3). There are only partial reviews on the occurrence of tarsal spatulate setae (Forbes, 1910; Miller, 1991; Hasenfuss, 1999), but the state of Ta3 and Ta4 spatulate is apparently restricted to the Heterogynidae, most of the Zygaenidae and, to a lesser extent, the Pterophoroidea (Hasenfuss, 1999).

Presence of an "occipital sclerite". A similar sclerite is recorded in $A$. infausta and P. mimica (Fänger et al., 1999; Fänger \& Naumann, 2001); its presence must be verified in other Zygaenoid groups as it is certainly missing in Z. carniolica.

Prothoracic shield. The prothoracic shield in Heterogynis has an unusual shape, which on the basis of the consulted literature is shared only with Somabrachys Kirby, 1892 (Somabrachyidae) (Powell, 1911; pers. obs.).

Absence of seta V1 on the prothorax. Among all lepidopterous families with free-living caterpillars this character is recorded only in the "Phaudinae", which otherwise show noticeable reduction of the number of setae, as they lack two tactile setae on the metathorax, one on abdominal segment 8 and most microsetae (Fänger et al., 1999). Whether the character is shared with other species of Heterogynis deserves confirmation. Seta V1 was not found on the coxae, although in some families, such as the Adelidae and the Psychidae, it is displaced onto the coxae of all thoracic segments (Hasenfuss, 1963). V1 is missing, however, from the prothorax in some leafmining larvae (cf. Grandi, 1933).

Posterior displacement of MV3 in A1. The unusual position of this seta is also recorded in $A$. infausta (Fänger \& Naumann, 2001), but it might have been overlooked in other lepidopterous larvae.

Anal pores. In Heterogynis the pore ALa is always absent. Gerasimov (1939) recorded this pore in Z. filipendulae, where it occurs only in first instar larvae. Tremewan (1985) and Fänger \& Naumann (2001) did not mention it in $Z$. trifolii and $A$. infausta, respectively. Fänger \& Naumann (2001) described the AVa pore in $A$. infausta as "a button-like campaniform sensillum". In Heterogynis this pore is larger than the other body pores and with the membrane sclerotized in the middle (Fig. 2c). In first instar larvae of $Z$. carniolica the AVa pore is shaped as in Heterogynis (pers. obs.).

Quiescent instar and hibernaculum. A quiescent instar is recorded in several species of Zygaenidae Chalcosiinae, Procridinae and Zygaeninae, the last two of which show a partially modified habitus (Pieszczek, 1906; Burgeff, 1921; Tarmann, 1983; Tremewan, 1985; Naumann, 1985; Guenin, 1997b; Naumann et al., 1999). The spinning of a hibernaculum is recorded for some Procridinae (Adscita Retzius, 1783, Rhagades Wallengren, 1863, Theresimima Strand, 1917 and Primilliberis Alberti, 1954) (Passerini, 1830; Russo, 1947; Tarmann, 1983; Wipking \& Naumann, 1992; Efetov \& Tarmann, 1995; Nishihara \& Wipking, 2003) and Chalcosiinae (Aglaope Latreille, 1809 and Elcysma Butler, 1881) (Silvestri, 1939-1942; Nakai \& Takeda, 1995). Illiberis (Primilliberis) pruni Dyar, 1905 enters diapause without moulting (Nishihara \& Wipking, 2003). Outside of the Zygaenoidea, only the Prodoxidae Lamproniinae appear to spin a hibernaculum (Davis, 1987c, 1999). The construction of a small cocoon for moulting is known in the Cyclotornidae (Zygaenoidea) and in the genus Bucculatrix Zeller, 1839 (Lyonetiidae); these, however, do not diapause in the cocoon (Davis, 1987b; Common, 1990).

Moulting. A probable synapomorphy of the Heterogynidae and Zygaenidae is the peculiar ecdysial line, that in Heterogynis is identical with that in Z. trifolii, Z. viciae ([Denis \& Schiffermüller], 1775), Z. carniolica and $Z$. filipendulae (Hellins, 1866; Briggs, 1873; pers. obs.). The process of moulting shares some similarities with the Dalceridae, which pull the head and prothorax out of the exuvia (Epstein, 1997).

\section{"Tineoid" traits of Heterogynis}

Meso- and metathoracic MV2 nearer to MV3 than to MV1. This is a very unusual condition in lepidopterous larvae, the distances MV1-MV2 and MV2-MV3 are usually nearly equal or the second is the greater. The same condition is recorded in some Tineidae by Davis (1987d: 264) and in Psyche Schrank, 1801 (Psychidae) by Hasenfuss (1963).

\section{Other characters of phylogenetic interest}

Absence of head proprioceptors V2, V3 and pore Va. This could be interpreted as an adaptation to the V-zone being permanently retracted into the prothorax and the proprioceptors loosing their usefulness. Similarly, Hinton (1946) tentatively attributed the loss of V3 in Pieris Schrank, 1801 (Pieridae) to its uselessness, although the head of Pieris larvae is never retracted into the prothorax. Within the Zygaenidae, the complete loss of V-setae and pores is evident in Artona Walker, 1854 (Procridinae) (cf. Yen et al., 1996: 101, 103), while in Pryeria sinica (Zygaeninae) only V3 is absent (Yen \& Horie, 1997).

Position of labral setae M1 and M2. Forbes (1910) used the character "labrum with $i$ no higher than $i i$ ", i.e. "M1 not proximal to M2", together with other larval 
characters, to define his "Zygaenina", comprising Heterogynidae, Zygaenidae, Megalopygidae and Limacodidae. As a representative of the Heterogynidae, he selected Heterogynis paradoxa (no author being indicated), stating "labrum with $i i$ strong, and no higher than $i$ ", i.e. M2 strong and not proximal to M1. Therefore, putting together both of Forbes' statements, it is concluded that he considered M1 and M2 in Heterogynis to be positioned on a same horizontal line. Forbes' observation does not correspond with our findings on $H$. penella and $H$. eremita, where $\mathrm{M} 1$ is distal to $\mathrm{M} 2$ as in the other "Zygaenina" examined by Forbes. There is doubt, however, about the identity of Forbes' $H$. paradoxa, because since Kirby (1892) this name was often used for $H$. penella (Hübner, [1819]) and not H. paradoxa Rambur, 1837 (Zilli \& Racheli, 1989). Research on the chaetotaxy of $H$. paradoxa Rambur, 1837 , is needed to resolve this ambiguity. Moreover, in some Zygaenidae, e.g. Pryeria sinica (cf. Yen \& Horie, 1997) and Zygaena lonicerae (Scheven, 1777) (Engel, 1927: 222), M1 is proximal to M2, while in Artona gracilis (Walker, 1864) the two setae are at the same level. M1 is distal to M2 in Dalceridae, Aididae (cf. Epstein, 1996), "Phaudinae" (Fänger et al., 1999) and Somabrachyidae (Somabrachys aegrota (Klug, 1830); pers. obs.), and this arrangement is rarely regular in whole families outside of the Zygaenoidea, with the exception of Sesioidea and Choreutidae (Popescu-Gorj et al., 1958; Heppner \& Duckworth, 1981; Heppner, 1982). However, this character occurs sparsely, particularly in lower Ditrysia. More widespread is the state in which M1 and M2 are at the same level, even if the commonest condition in lepidopterous larvae is M1 proximal to M2.

Epipharyngeal lamella. A tongue-shaped lamella external to the epipharyngeal sensilla of the labrum is recorded or simply figured in several groups of Lepidoptera, e.g. Psychidae (Baker, 1990; Davis \& Robinson, 1999), Acrolepiidae (Al-Rhouz \& Thibout, 1989), Tortricidae (Albert, 1980) and Pyralidae (Faucheux, 1995), but its function has not been thoroughly investigated. Concerning the Zygaenoidea, an ephipharyngeal lamella is also evident in the SEM photomicrographs of Aidos sp. (Aididae) in Epstein (1996: Fig. 130) and Aglaope infausta (Zygaenidae) in Fänger \& Naumann (2001: Fig. 29). In Heterogynis this structure cannot be easily detected, and probably has been overlooked in other Lepidoptera.

Chapman's organ. The organ found in Heterogynis larvae is reminiscent of the "pit" observed by Aitkenhead \& Baker (1964) in first instar larvae of Hepialidae. A small sclerite, probably representing a vestige of the organ, is present in first instar larvae of $Z$. carniolica (pers. obs.). Moreover, Dickson (1961) and Bode \& Naumann (1987) described a glandular organ in Neurosymploca larvae (Zygaeninae) in a similar position on T2 as Chapman's organ. However, the organ in Neurosymploca lacks a sclerite and persists after the first moult and in some species it occurs on body segments other than T2. The same occurs in Artona funeralis (Butler, 1879) (Pro- cridinae) (cf. Yen et al., 1996). To assess the homology of all these structures would require histological investigations, so Chapman's organ is tentatively considered to be a plesiomorphic trait of Heterogynis.

Crochets. In the light of the evolutionary trends in crochet configuration (cf. Common, 1975), the arrangement shown by Heterogynis (uniordinal mesal partial circle) is considered to be plesiomorphic relative to the uniordinal mesoseries shown by the Zygaenidae, Cyclotornidae, Megalopygidae (where crochet series may be divided), Somabrachyidae (always divided) and crochet-bearing Limacodidae, the multiordinal mesoseries of Himantopteridae (divided) and the mesal V-shaped row of Aididae (uniordinal) and "Phaudinae" (Phauda: anterior branch of the "V" uniordinal, posterior biordinal) (Common, 1990; Epstein, 1996; Epstein et al., 1999; Fänger et al., 1999; Fänger \& Fänger, 2000; Geertsema, 2002). A crochet arrangement similar to that in Heterogynis occurs in Dalceridae (Stehr \& McFarland, 1987; Epstein, 1996), but members of this family, Megalopygidae, Somabrachyidae and Aididae, show additional prolegs on A2 and A7, which are considered to be an autapomorphy of the "Limacodid group" (Epstein, 1996). In this respect, the uniordinal circle of crochets in the Epipyropidae (Kato, 1940 ) is noteworthy and likely resulting from selection for grasping at their hosts.

Spinneret. Heterogynis shares a spinneret of tubular type with most of the Glossata, including the Zygaenoidea except for the Dalceridae and Limacodidae, in which it is brush-like (Epstein, 1996).

Setae. Heterogynis larvae appear plesiomorphic relative to most other Zygaenoidea, in having only slightly modified (plumose) body setae, i.e. not strongly modified as in the Limacodidae and Dalceridae, and lacking secondary setae, widespread in Zygaenidae, Megalopygidae, Himantopteridae, Somabrachyidae, Aididae, Epipyropidae, Cyclotornidae and some Limacodidae (Davis, 1987e; Stehr, 1987b, 1987c; Common, 1990; Epstein et al. 1999). Nevertheless, the "Phaudinae" also lack secondary setae, and their primary setae are smooth and simple in shape, with the exception of the dorsal and subdorsal setae on T3-A8 that are truncate, probably because of a tergal cap covering these segments (Fänger et al., 1999).

Ventral displacement of MSD setae. In Heterogynis, MSD1 and MSD2 are clearly displaced ventrally, those on the mesothorax are on the same level as the prothoracic spiracle. A ventral displacement of MSD setae is recorded by Tremewan (1985) for Z. trifolii and Fänger \& Naumann (2001) for A. infausta, and is paralleled in Eriocrania Zeller, 1851 (Eriocraniidae) and most Tineidae (Hasenfuss, 1963).

\section{CONCLUSIONS}

The larval morphology allows one to define the Heterogynidae in terms of the presumptive autapomorphy that has been identified in the chaetotaxy, viz. presence of two primary setae on the inner side of the prolegs. The heterogynid larva retains several plesiomorphic traits (e.g. no secondary setae, crochets in mesal partial circle), but 
some characters suggest a closer relationship between Heterogynidae and Zygaenidae than other family groups. Of the characters it is worth stressing the compartmentalised cuticle, the presence of a single MV-seta on the prothorax, the tarsal setae Ta3 and Ta4 spatulate, the mode of larval ecdysis and that they diapause in a silken hibernaculum. Nevertheless, a full appreciation of the systematic value of these characters is hampered by a limited knowledge of their state in other groups. Concerning the cuticular cavities, Patton (1891), Common (1990) and Epstein $(1996,1997)$ report the release of defensive droplets from pores in other Zygaenoidea (Limacodidae, Dalceridae and Lacturidae), while Fänger \& Naumann (2001) demonstrated that cuticular cavities lacking discharge pores can also occur (in Aglaope, Zygaenidae Chalcosiinae). This fact, together with the similarity between the coronetted tubercles of Heterogynis and the apices of the tubercles in Apoda (see Discussion), calls for a further investigation of the presence of cuticular cavities in the Limacodidae and other Zygaenoidea. As regards the reduced number of $\mathrm{MV}$-setae on the prothorax, this trait is known to occur in some leaf-miners (cf. Common, 1980), but has not been extensively investigated in freeliving caterpillars. Also the occurrence of spatulate tarsal setae and the mode of larval ecdysis would require a thorough review across other families. For instance, moulting in the Dalceridae is reminiscent of that in Heterogynidae and Zygaenidae (cf. Epstein, 1997). The state of Ta3 and Ta4 spatulate (cf. Stehr, 1987b) and the building of a silken hibernaculum, moreover, are not shared with all the Zygaenidae, and the occurrence of a silken hibernaculum in some Monotrysia (Davis, 1987c, 1999) at least indicates that the character can arise independently. It should be noticed that the linking of the Heterogynidae with the Zygaenidae would lead to considering the shared pattern of MV-setae on T2-T3 in the Heterogynidae and some Tineoidea as homoplasious or symplesiomorphic; this relates also to some characters of the adult such as the tineoid-type abdominal sternum 2 (Zilli, 1998).

On the other hand, the absence of V1 on prothorax suggests that the Heterogynidae should be linked to the "Phaudinae", which were indicated by Fänger et al. (1999) as the probable sister-group of the limacodidgroup families of the Zygaenoidea. This hypothesis would be further corroborated by characters of the adult such as the reduction of the proboscis and absence of ocelli, which are considered synapomorphic for the "Phaudinae" and the limacodid group (Epstein, 1996; Fänger et al., 1999). It should be noticed here that Scoble's (1992: 37) recording of the ocelli in the Heterogynidae relates to Janseola, no more included in the family (Zilli, 1998). Nevertheless, considering that Zygaenidae, Heterogynidae and "Phaudinae" share the same relative lengths of stemmatal setae S1 and S2 (microscopical and macroscopical, respectively), while $\mathrm{S} 2$ is reduced in the limacodid group, there is clear evidence that some homoplasious characters are included in current analyses, and this is hampering the phylogenetical reconstruction of the Zygaenoidea.
As a matter of fact, also the monophyly of the Zygaenoidea remains unclear because of the unsatisfactory definition of the superfamily as a whole. Most of the larval characters used to define the Zygaenoidea have to be reconsidered (head retractability; heteromorphosis; forward migration and reduction in size of head setae), while other possibly useful characters (e.g. position of microsetae and pores; labral sensilla) have not been fully investigated in all zygaenoid families. Moreover, for a number of families (e.g. Anomoeotidae, Lacturidae) there is little information, so that it is not feasible to use larval characters to comment on Gomez Bustillo's (1980) hypothesis that the Heterogynidae and Anomoeotidae are closely related (see Fänger et al., 1999, for other views on the phylogenetic relationships of the Anomoeotidae). The resolution of the systematic relationships between the zygaenoid families and the relation of the Zygaenoidea with their putative sister group (Cossoidea + Sesioidea) therefore remain to be resolved.

ACKNOWLEDGEMENTS. We are deeply indebted to W. Gerald Tremewan (Truro, Great Britain) for both revising the English style of the manuscript and having shared with the authors his knowledge of the Zygaenoidea. A grateful thank you goes also to two anonymous referees and a language editor for their useful comments.

\section{REFERENCES}

Aitkenhead P. \& Baker C.R.B. 1964: The larvae of British Hepialidae. The Entomologist 97: 25-38.

Albert P.J. 1980: Morphology and innervation of mouthpart sensilla in larvae of the spruce budworm, Choristoneura fumiferana (Clem.) (Lepidoptera: Tortricidae). Can. J. Zool. 58: $842-851$.

Al-Rhouz H. \& Thiвout E. 1989: Morphologie des sensilles céphaliques larvaires d'Acrolepiopsis assectella Zell. (Lepidoptera: Hyponomeutoïdea). Annls Soc. Entomol. Fr. (n.s.) 25: $163-170$.

BAKER G.T. 1990: Morphology of eyes and sensory receptors of larval and adult stages of Thyridopteryx ephemeraeformis Haworth (Lepidoptera: Psychidae). Miss. Agric. Forest Exp. Stat. Tech. Bull. 170: 1-12.

Bode W. \& Naumann C.M. 1987: Structure of a newly discovered glandular organ in Neurosymploca larvae (Lepidoptera: Zygaenidae). Zool. Jb. (Anatomie) 115: 319-329.

BollmanN H.-G. 1955: Die Raupen mitteleuropäischer Pyraustinae (Lepidoptera: Pyralidae). Beitr. Entomol. 5: 521-639.

BÖRNER C. 1939: Die Grundlagen meines Lepidopterensystems. Verhandlungen VII. Int. Kong. Entomol., Berlin 1938 2: $1372-1424$

BRIGGS T.H. 1873: Note on the larva of Zygaena meliloti. Entomol. Mon. Mag. 10: 116-117.

BRock J.P. 1971: A contribution towards an understanding of the morphology and phylogeny of the ditrysian Lepidoptera. J. Nat. Hist. 5: 29-102.

BRuAND T., D'Uzelle 1853: Essai monographique sur la tribu des Psychides. Mém. Soc. Emul. Doubs (2) 3: 17-127, pls $1-3$.

BurgefF H. 1921: Beiträge zur Biologie der Gattung Zygaena F. (Anthrocera Scop.) IV. Mitt. Münch. Entomol. Ges. 11: 50-64.

Chapman T.A. 1894: Some notes on the Micro-Lepidoptera whose larvae are external feeders, and chiefly on the early stages of Eriocephala calthella (Zygaenidae, Limacodidae, 
Eriocephalidae). Trans. Entomol. Soc. London 1894: 335-350, pls 6-7.

Chapman T.A. 1898: Some remarks on Heterogyna penella. Trans. Entomol. Soc. London 1898: 141-150.

Chapman T.A. 1902: On Heterogynis paradoxa, Rmbr, an instance of variation by segregation. Trans. Entomol. Soc. London 1902: 717-729, pl. 28.

Chapman T.A. 1904: Notes on Heterogynis canalensis, n. sp. Trans. Entomol. Soc. London 1904: 71-79, pls 11-14.

Chapman T.A. 1905: On the matrivorous habit of the species of Heterogynis, Rmbr. Trans. Entomol. Soc. London 1905: 177-184.

Chapman T.A. 1916: Apterousness in Lepidoptera. Trans. London Nat. Hist. Soc. 1916: 49-76.

CHENU J.C. 1851-1853: Encyclopédie d'Histoire Naturelle, Papillons 1. Marescq et comp., Paris, 310 pp., 40 pls.

Christensen P.J.H. 1950: Studien über die postembryonale Entwicklung bei Cochlidion limacodes Hufn. (Fam. Cochlididae, Lepidoptera). Biol. Skrift. 7: 1-34, pls. 1-9.

Common I.F.B. 1970: Lepidoptera (Moths and Butterflies). In: CSIRO (ed.): The Insects of Australia. Melbourne Univ. Press, Melbourne, pp. 765-866.

Common I.F.B. 1975: Evolution and classification of the Lepidoptera. A. Rev. Entomol. 20: 183-203.

Common I.F.B. 1980: The systematic position of Hypertropha (Lepidoptera) and related Australian genera. Entomol. Scand. 11: $17-31$.

Common I.F.B. 1990: Moths of Australia. Melbourne Univ. Press, Carlton, 535 pp., 32 pls.

Daniel F. 1966: Heterogynis andalusica sp. n. (Lep.- Heterogynidae). Z. Wien. Entomol. Ges. 51: 101-103.

Daniel F. \& Dierl W. 1966: Zur Biologie und Anatomie von Heterogynis penella (Hbn.) (Lep.). Zool. Anz. 176: 447-464.

Davis D.R. 1987a: Psychidae (Tineoidea). In: Stehr F.W. (ed.): Immature Insects, Vol. 1. Kendall/Hunt, Dubuque, pp. 366-369.

Davis D.R. 1987в: Lyonetiidae (Tineoidea). In: Stehr F.W. (ed.): Immature Insects, Vol. 1. Kendall/Hunt, Dubuque, pp. 370-372, 375-376.

DAVIS D.R. 1987c: Prodoxidae (Incurvarioidea). In: Stehr F.W (ed.): Immature Insects, Vol. 1. Kendall/Hunt, Dubuque, pp. 359-362.

DAvIS D.R. 1987d: Tineidae (Tineoidea). In: Stehr F.W. (ed.): Immature Insects, Vol. 1. Kendall/Hunt, Dubuque, pp. $362-365$.

DAVIS D.R. 1987e: Epipyropidae (Zygaenoidea). In: Stehr F.W. (ed.): Immature Insects, Vol. 1. Kendall/Hunt, Dubuque, pp. 456, 459-460.

Davis D.R. 1999: The Monotrysian Heteroneura. In: Kristensen N.P. (ed.): Handbuch der Zoologie, Vol. 4. Lepidoptera, Moths and Butterflies, Part 1. W. De Gruyter, Berlin, pp. 65-90.

Davis D.R. \& Robinson G.R. 1999: The Tineoidea and Gracillarioidea. In: Kristensen N.P. (ed.): Handbuch der Zoologie, Vol. 4. Lepidoptera, Moths and Butterflies, Part 1. W. De Gruyter, Berlin, pp. 91-117.

Dethier V.G. 1939: The antennae of lepidopterous larvae. Bull. Mus. Compar. Zool. 87: 455-507, pls 1-9.

Dickson C.G.C. 1961: Notes on the early stages of Neurosymploca affinis Jord. (Lepidopt.: Zygaenidae). J. Entomol. Soc. S. Afr. 24: 212-213

DyAR H.G. 1895: A combination of two classifications of Lepidoptera. J. N.Y. Entomol. Soc. 3: 17-26.

EFetov K.A. 1994: The biology and description of the larva of Adscita (Zygaenoprocris) minna Efetov, 1991 (Lepidoptera: Zygaenidae, Procridinae). Entomol. Gaz. 45: 115-121.
Efetov K.A. \& TARMann G.M. 1995: An annotated check-list of the palaearctic Procridinae (Lepidoptera: Zygaenidae), with descriptions of new taxa. Entomol. Gaz. 46: 63-103.

Efetov K.A. \& Tarmann G.M. 1999: Forester Moths. Apollo Books, Stenstrup, 192 pp.

ENGEL H. 1927: Vergleichende morphologische Studien über die Mundgliedmassen von Schmetterlingsraupen. Z. Morph. Ökol. Tiere 9: 166-270.

EPSTEIN M.E. 1996: Revision and phylogeny of the Limacodidgroup families, with evolutionary studies on slug caterpillars (Lepidoptera: Zygaenoidea). Smithson. Contr. Zool. No. 582, i-iii, 1-102.

EpsteIN M.E. 1997: Biology of Dalcerides ingenita (Lepidoptera: Dalceridae). Trop. Lepidopt. 8: 49-59.

Epstein M., Geertsema H., Naumann C.M. \& Tarmann G.M. 1999: The Zygaenoidea. In: Kristensen N.P. (ed.): Handbuch der Zoologie, Vol. 4. Lepidoptera, Moths and Butterflies, Part 1. W. De Gruyter, Berlin, pp. 159-180.

FÄNGER K. \& FäNGER H. 2000: Life history, morphology and taxonomy of Somabrachys aegrota (Klug, 1830) in Tunisia (Lepidoptera: Somabrachyidae). Entomol. Z. 110: 73-78.

Fänger H. \& NaUmanN C.M. 2001: The morphology of the last instar larva of Aglaope infausta (Lepidoptera: Zygaenidae: Chalcosiinae). Eur. J. Entomol. 98: 201-218.

Fänger H., Yen S.-H. \& NAUMANn C.M. 1999: External morphology of the last instar larva of Phauda mimica Strand, 1915 (Lepidoptera, Zygaenoidea). Entomol. Scand. 29: 429-450.

FAUCHEUX M.J. 1995: Sensilla on the larval antennae and mouthparts of the European Sunflower Moth, Homoeosoma nebulella Den. and Schiff. (Lepidoptera: Pyralidae). Int. J. Insect Morph. \& Embryol. 24: 391-403.

ForBes W.T.M. 1910: A structural study of some caterpillars. Annls Entomol. Soc. Am. 3: 94-143.

FreinA DE J.J. 2003a: Zur Kenntnis der Biologie, Morphologie und Taxonomie von Heterogynis andalusica Daniel, 1966 sowie ergänzenden Bemerkungen zum Status von Heterogynis thomas Zilli, 1987 stat. rev. (Lepidoptera: Zygaenoidea: Heterogynidae). Atalanta 34: 179-192, pls $15-19$.

Freina DE J.J. 2003b: Heterogynis jellaba spec. nov. und Heterogynis rifensis spec. nov., zwei neue nordafrikanische Heterogynis-Arten aus Marokko mit ergänzenden Bemerkungen zum Verbreitungsbild und Artenspektrum der Gattung Heterogynis Rambur, 1837 (Lepidoptera: Zygaenoidea: Heterogynidae). Atalanta 34: 193-208, pls 16-19.

Freina De J.J. \& Witt T.J. 1990a: Die Bombyces und Sphinges der Westpalaearktis (Insecta, Lepidoptera) 2. Forschung \& Wissenschaft, München, 140 pp.

FreINA DE J.J. \& WitT T.J. 1990b: Exzeptionelle und partielle Parthenogenese bei Heterogyniden. Beschreibung der ersten Larvalstände und des Weibchens von Heterogynis andalusica thomas Zilli, 1987 (Lepidoptera: Heterogynidae). Nota Lepidopterol. 13: 129-132.

Geertsema H. 2002: An overview of the African flannel moths (Somabrachyidae) (Zygaenoidea: Lepidoptera), including their putative relationships. Afr. Entomol. 10: 285-295.

Geertsema H., Naumann C.M. Tarmann G., Epstein M.E., Miller S.E. \& Zilli A. 1996: Advances in the phylogenetic study of the Zygaenoidea. Proc. XX Int. Cong. Entomol., Firenze 1996: 32.

Gerasimov A.M. 1939: Die Chaetotaxie des Analsegments der Raupen. Z. Öst. EntomolVer. 24: 36-39, 50-59, 71-78.

Gerasimov A.M. 1952: Fauna of the USSR, n.s., 56. Insecta Lepidoptera, Part 1. Caterpillars. Akademiya Nauk SSSR, Moskva \& Leningrad, 338 pp. [in Russian] 
Gómez Bustillo M.R. 1980: Revisión de la familia Heterogynidae (Kirby, 1892) en la Península Ibérica (Lep.: Zygaenoidea). SHILAP Rev. Lepidopterol. 8: 232-236.

Grandi G. 1930: Hypopta caestrum Hbn. Boll. Lab. Entomol. R. Istit. Agr. Bologna 3: 221-244, pl. 3.

Grandi G. 1931: Obliterazione, atrofia e spostamento di organi in un lepidottero ad etologia specializzata. Mem. R. Accad. Sci. Istit. Bologna (Scienze Fisiche: Scienze Naturali) (8) 8: 17-21, pl. 1.

Grandi G. 1933: Morfologia ed etologia comparata di insetti a regime specializzato. IV. La morfologia comparata di vari stati larvali di 30 microlepidotteri minatori appartenenti a 15 generi ed a 11 famiglie. Boll. Lab. Entomol. R. Istit. Agr. Bologna 5: 143-307.

GRASLIN DE A. 1850: Notice sur quelques Lépidoptères nouveaux trouvés dans les Pyrénées orientales en 1847. Annls Soc. Entomol. Fr. (2) 8: 391-416, pl. 10.

Grimes L.R. \& Neunzig H.H. 1986a: Morphological survey of the maxillae in last stage larvae of the suborder Ditrysia (Lepidoptera): palpi. Annls Entomol. Soc. Am. 79: 491-506.

Grimes L.R. \& Neunzig H.H. 1986b: Morphological survey of the maxillae in last stage larvae of the suborder Ditrysia (Lepidoptera): mesal lobes (Laciniogaleae). Annls Entomol. Soc. Am. 79: 510-526.

GRYSE DE J.J. 1915: Some modifications of the hypopharynx in lepidopterous larvae. Proc. Entomol. Soc. Washington 17: 173-179.

GuENIN R. 1997a: Heterogynidae. In: LepidopterologenArbeitsgruppe: Schmetterlinge und ihre Lebensräume, Vol. 2. Pro Natura, Basel, pp. 309-312.

GuENIN R. 1997b: Zygaenidae. In: LepidopterologenArbeitsgruppe: Schmetterlinge und ihre Lebensräume, Vol. 2. Pro Natura, Basel, pp. 313-430.

HASENFUSS I. 1963: Eine vergleichend-morphologische Analyse der regulären Borstenmuster der Lepidopterenlarven. Studien zur Methodik der vergleichenden Morphologie der Borstenmuster und zur phylogenetischen Deutung der Abwandlungen der regulären Borstenmuster der Lepidopterenlarven. $Z$. Morph. Ökol. Tiere 52: 197-364.

Hasenfuss I. 1969: Zur Homologie der Borstenmusterelemente der Larven-Kopfkapsel einiger monotrysischer Lepidoptera. Beitr. Entomol. 19: 289-301.

Hasenfuss I. 1980: Die Präimaginalstadien von Thyris fenestrella Scopoli (Thyrididae, Lepidoptera). Bonn. Zool. Beitr. 31: $168-190$.

HasenfuSS I. 1999: The adhesive devices in larvae of Lepidoptera (Insecta: Pterygota). Zoomorphology 119: 143-162.

HeInRICH C. 1916: On the taxonomic value of some larval characters in the Lepidoptera. Proc. Entomol. Soc. Washington 18: $154-164$

HeINRICH C. 1921: On some forest Lepidoptera with descriptions of new species, larvae, and pupae. Proc. United States Nat. Mus. 57: 53-96, pls 1-13.

Hellins J. 1866: Note on hybernation and moulting of Anthrocera trifolii. Entomol. Mon. Mag. 3: 18-19.

HeppNER J.B. 1982: Millieriinae, a new subfamily of Choreutidae, with new taxa from Chile and the United States (Lepidoptera: Sesioidea). Smithson. Contr. Zool. No. 370: i-iii, $1-27$.

Heppner J.B. 1984: Atlas of Neotropical Lepidoptera. Checklist: Part I. Dr W. Junk, The Hague, xxvii + 112 pp.

Heppner J.B. 1993: Key to families of Lepidoptera. Trop. Lepidopt. 4: 1-28.

HePPNER J.B. 1995: Lacturidae, new family (Lepidoptera: Zygaenoidea). Trop. Lepidopt. 6: 146-148.
HeppNer J.B. \& Duckworth W. 1981: Classification of the superfamily Sesioidea (Lepidoptera: Ditrysia). Smithson. Contr. Zool. No. 314: i-iii, 1-144.

HeppNer J.B. \& INOUE H. 1992: Lepidoptera of Taiwan, 1.2: Checklist. Association for Tropical Lepidoptera \& Scientific Publishers, Gainesville, xlix +276 pp.

Hinton H.E. 1946: On the homology and nomenclature of the setae of lepidopterous larvae, with some notes on the phylogeny of the Lepidoptera. Trans. R. Entomol. Soc. London 97: 1-37.

Hinton H.E. 1958: The phylogeny of the panorpoid orders. $A$. Rev. Entomol. 3: 181-206.

Hopp W. 1923: Eine Heterogynide in Südafrika (Lep.). Dt. Entomol. Z. 1923: 244-245.

KARSCH F. 1898 Giebt es ein System der recenten Lepidopteren auf phyletischer Basis? Entomol. Nachr. 24: 296-303.

Kато M. 1940: A monograph of Epipyropidae (Lepidoptera). Entomol. World 8: 67-94, pls 1-4. [in Japanese]

KIRBY W.F. 1892: A Synonymic Catalogue of Lepidoptera Heterocera: (Moths) 1, Sphinges and Bombyces. Gurney \& Jackson, London, xii $+951 \mathrm{pp}$.

KozhantschiKov I.B. 1956: Fauna of the USSR, n. s., No. 52. Insecta Lepidoptera. Fam. Psychidae. Akademiya Nauk SSSR, Moskva \& Leningrad, 517 pp. [in Russian]

KRISTENSEN N.P. \& SKALSKI A.W. 1999: Phylogeny and palaeontology. In: Kristensen N.P. (ed.): Handbuch der Zoologie, Vol. 4. Lepidoptera, Moths and Butterflies, part 1. W. De Gruyter, Berlin, pp. 7-25.

McIndoo N.E. 1919: The olfactory sense of lepidopterous larvae. Ann. Entomol. Soc. Am. 12: 65-84.

McIndoo N.E. 1929: Tropisms and sense organs of Lepidoptera. Smithson. Misc. Collns 81: 1-59.

Miller J.S. 1991: Cladistics and classification of the Notodontidae (Lepidoptera: Noctuoidea) based on larval and adult morphology. Bull. Am. Mus. Nat. Hist. 204: 1-230.

Miller S.E. 1994: Systematics of the neotropical moth family Dalceridae (Lepidoptera). Bull. Mus. Comp. Zool. 153: 301-495.

Minet J. 1986: Ébauche d'une classification moderne de l'ordre des Lépidoptères. Alexanor 14: 291-313.

Minet J. 1991: Tentative reconstruction of the ditrysian phylogeny (Lepidoptera: Glossata). Entomol. Scand. 22: 69-95.

NAKAI T. \& TAKEDA M. 1995: Effect of temperature on the estivation of Elcysma westwoodi (Lepidoptera: Zygaenidae). Appl. Entomol. Zool. 30: 594-596.

NAUMANN C.M. 1985: Zur Ökologie und Biologie von Zugaena [sic] (Zygaena) christa Reiss \& Schulte, 1967. Nota Lepidopterol. 8: 42-50.

Naumann C.M. 1988 The internal female genitalia of some Zygaenidae (Insecta: Lepidoptera): their morphology and remarks on their phylogenetic significance. System. Entomol. 13: 85-99.

NAUMANN C.M. \& Feist R. 1987: The structure and distribution of cyanoglucoside-storing cuticular cavities in Pryeria sinica Moore (Lepidoptera, Zygaenidae). Zool. Scr. 16: 89-93.

NAumann C.M. \& PovolnÝ D. 1987: Zur Lagebeziehung und Funktion von Wehrsekretbehältern und Sinneshaaren im larvalen Integument von Zygaena. Entomol. Abhand. 50: 193-198.

Naumann C.M., Tarmann G.M. \& Tremewan, W.G. 1999: The Western Palaearctic Zygaenidae. Apollo Books, Stenstrup, $304 \mathrm{pp}$.

NishiHARA K. \& WIPKING W. 2003: The biology and early stages of the apple moth Illiberis (Primilliberis) pruni Dyar, 1905 (Lepidoptera: Zygaenidae, Procridinae) in Japan. In: Efetov K.A. et al. (eds): Proc. 7th Int. Symp. Zygaenidae (Lepidop- 
tera), Innsbruck (Austria) 2000. Crimean State Medical University Press, Simferopol, pp. 109-126.

Passerini C. 1830: Sopra due specie d'insetti nocivi, uno alla vite, il brucio della Procris ampelophaga; e l'altro al cavolo arboreo, la larva, o baco del Lixus octolineatus. Atti Ist. R. Accad. Econom.Agr. Georg. Firenze 8: 11-23, pl. 1.

PatTon W.H. 1891: Scent-glands in the larva of Limacodes. Can. Entomol. 23: 42-43.

PieszCZeK H. 1906: Über eine Zucht der interessanten Zygaena Ephialtes ab. aeacus Esp. Verh. Kaiser.Königl. Zool.-Bot. Ges. Wien 56: 12-14.

Popescu-Gorj A., Niculescu E. \& AleXINSChi A. 1958: Fauna of the People's Republic of Rumania, Vol. 11, No. 1. Lepidoptera family Aegeriidae. Editura Academiei Republicii Populare Romîne, Bucarest, 195 pp., 5 pls. [in Rumanian]

Powell H. 1911: Documents concernant les Somabrachys. In: Oberthür C. (ed.): Études de Lépidoptérologie Comparée, Vol. 5. Imprimerie Oberthür, Rennes, pp. 227-340, pls 84-85 + A-D.

RAMBUR J.P. 1837: Notice sur plusieurs Lépidoptères du midi de l'Espagne, parmi lesquels se trouve le Papillon Eupheme d'Esper. Annls Soc. Entomol. Fr. 5: 573-588, pl. 17.

Rebel H. 1898: Ueber den gegenwärtigen Stand der Lepidopteren-Systematik. Dt. Entomol. Z. Iris 11: 377-391.

RIPLEY L.B. 1923: The external morphology and postembryology of Noctuid larvae. Illinois Biol. Monogr. 8: 1-85, pls $1-8$.

Russo G. 1947: La Zigena della vite nell'Isola d'Elba (Theresimima (= Ino) ampelophaga) Lepidottero Zygaenidae. Annali Fac. Agr. Univ. Pisa (n.s.) 8: 51-55.

Schmidt F.J. 1860: Heterogynis dubia. Ein für Österreich neuer Schmetterling. Verh. Kaiser.Königl. Zool.-Bot. Ges. Wien 10: 659-662.

Scoble M. 1992: The Lepidoptera: Form, Function and Diversity. Natural History Museum Publications \& Oxford University Press, Oxford, xi +404 pp.

Seitz A. \& Gaede M. 1926: Heterogynidae. In: Seitz A. (ed.): Die Gross-Schmetterlinge der Erde, Vol. 14. A. Kernen, Stuttgart, pp. 39-40.

Silvestri F. 1939-1942: Compendio di Entomologia Applicata: Agraria, Forestale, Medica, Veterinaria, 2. Tipografia Bellavista, Portici, 699 pp.

STEHR F.W. 1987a: Order Lepidoptera. In: Stehr F.W. (ed.): Immature Insects, Vol. 1. Kendall/Hunt, Dubuque, pp. 288-305.

Stehr F.W. 1987b: Zygaenidae (Zygaenoidea). In: Stehr F.W. (ed.): Immature Insects, Vol. 1. Kendall/Hunt, Dubuque, pp. 453-454.

Stehr F.W. 1987c: Megalopygidae (Zygaenoidea). In: Stehr F.W. (ed.): Immature Insects, Vol. 1. Kendall/Hunt, Dubuque, pp. $454-456$.

Stehr F.W. \& Martinat P.J. 1987: Lepidoptera: key to families of larvae. In: Stehr F.W. (ed.): Immature Insects, Vol. 1. Kendall/Hunt, Dubuque, pp. 306-340.
Stehr F.W. \& McFarland N. 1987: Dalceridae (Zygaenoidea). In Stehr F.W. (ed.): Immature Insects, Vol. 1. Kendall/Hunt, Dubuque, pp. 460-462.

TARMANN G. 1983: Zur Biologie und Zucht von Rhagades (Rhagades) amasina (Herrich Schäffer, 1852) (Lepidoptera: Zygaenidae). Entomofauna 4: 157-163.

Tremewan W.G. 1985: Zygaenidae. In: Heath J. \& Emmet A.M. (eds): The Moths and Butterflies of Great Britain and Ireland, Vol. 2. Harley Books, Colchester, pp. 74-123.

WiPKING W. \& NAUMANN C.M. 1992: Diapause and related phenomena in Zygaenidae moths. In: Dutreix C. et al. (eds): Proc. 4th Symp. Zygaenidae, Nantes 11-13 September 1987. Koeltz Scientific Books, Koenigstein, pp. 107-128.

Witthohn K. \& Naumann C.M. 1984: Die Verbreitung des $\beta$-cyan-L-alanin bei cyanogenen Lepidoptera. Z. Naturf. 39c: 837-840.

Yen S.-H. \& HoRIE K. 1997: Pryeria sinica Moore (Lepidoptera, Zygaenidae), a newly discovered relic in Taiwan. Trans. Lepidopterol. Soc. Japan 48: 39-48.

Yen S.-H., Jean J.-L. \& Yang P.-S. 1996: On two Artona species from Taiwan (Lepidoptera: Zygaenidae, Procridinae). Entomol. Gaz. 47: 99-108.

YeN S.-H. 2003: Phylogeny and systematics of the major lineages of Chalcosiinae s.l. (Zygaenidae s.1.): preliminary observations on morphological characters. In: Efetov K.A. et al. (eds): Proc. 7th Int. Symp. Zygaenidae (Lepidoptera), Innsbruck (Austria) 2000. Crimean State Medical University Press, Simferopol, pp. 293-348.

Zilli A. 1987: Osservazioni sulle Heterogynis Rambur, 1837 dell'Africa settentrionale e descrizione di una nuova specie (Lepidoptera, Zygaenoidea, Heterogynidae). Fragm. Entomol. 20: $33-43$.

ZiLLi A. 1998: Towards a redefinition of the Heterogynidae: a comparison between Heterogynis and Janseola (Zygaenoidea). XI Eur. Cong. Lepidopterol., Malle (Belgium) 1998, pp. 110-111.

ZILLI A. 2002: Clinal variation of a reproductive isolating mechanism in a sedentary moth from South-Western Alps (Lepidoptera: Heterogynidae). XII Eur. Cong. Lepidopterol., Korsør (Denmark) 2002, p. 64.

Zilli A., Cianchi R., Racheli T. \& Bullini L. 1988a: A new species from southern Italy in the Heterogynis penella complex (Lep., Zygaenoidea, Heterogynidae). Boll. Mus. Reg. Sci. Nat. Torino 6: 1-9.

Zilli A., Cianchi R., Racheli T. \& Bullini L. 1988b: Ricerche sulla biologia e sul differenziamento genetico nel complesso Heterogynis penella (Lepidoptera, Zygaenoidea, Heterogynidae). Atti XV Cong. Nazion. Ital. Entomol., L'Aquila 1988, pp. 801-808.

ZiLli A. \& Racheli T. 1989: Revisional notes on Spanish Heterogynis Rambur, 1837 (Lepidoptera, Heterogynidae). Entomol. Gaz. 40: 125-152.

ZILLI A. \& RACHELI T. 1990: Gregariousness, apterism, matrivory, and the natural history of a moth (Lepidoptera: Heterogynidae). Animal \& Human Biol. 2: 7-40.

Received May 15, 2003; revised August 18, 2003; accepted November 6, 2003 